\title{
THE ALLOTROPIC FORMS OF SELENIUM ${ }^{\mathrm{r}}$
}

\author{
BY A. P. SAUNDERS
}

\section{INDEX}

I. Introduction.

II. List of References.

III. The Forms of Selenium (in brief).

IV. Purification of the Material.

V. Properties and Transformations of the different Forms.

I. Vitreous selenium.

Dilatometer measurements.

Electrical properties.

Refraction and dispersion.

Diathermancy.

2. Soluble selenium.

3. Amorphous selenium.

Behavior in solvents.

4. Crystalline red selenium.

5. Metallic selenium.

6. Heat conductivity.

7. Heat of transformation.

8. Specific heat.

9. Specific gravities.

Io. Conductivity.

I I. Coefficient of expansion.

VI. General properties of the Element.

I. Atomic weight.

2. Boiling-point.

3. Vapor density.

4. Spectrum.

5. Absorption spectrum.

6. Capillarity constant.

VII. Conclusion.

${ }^{1}$ The change to selenion advocated in Watts' Dictionary because of the pseudo-metallic character of the element seems unnecessary; the statement made there to the effect that Berzelius so named it, is incorrect. Berzelius called it selenium while expressly recognizing it as pseudo-metallic, between sulphur and tellurium. 


\section{INTRODUCTION}

The present investigation was taken up for the purpose of establishing the general relationships of the allotropic forms of selenium, and of determining their limits of stability. The descriptions commonly given are confusing because no systematic study of the subject has ever been made. The only available data which could lead to any conclusions are those relating to specific gravities, but these have often been determined without sufficient attention being paid to the methods by which the materials were prepared, or the conditions under which accurate results can be expected. Since none of the textbooks give any adequate review of the literature dealing with this element, it is proposed to gather together here a few notes on the principal memoirs which have appeared since the discovery of selenium in I8I8. This review will be strictly limited to those which deal with the properties of the element itself, neglecting those devoted to its compounds.

For convenience in discussing the earlier memoirs, the conclusions to which the present investigation has led, are given below, after the list of references to the literature. Following these there comes a description of the method of purification used, and then a discussion of the results previously recorded in the literature and those which the present experiments have brought out; these experiments include specific gravity determinations, dilatometric measurements, experiments on the behavior of selenium in liquids and miscellaneous observations; here follow also sections on the heat of transformation, specific heat, conductivity, etc. Finally, there will be found a section devoted to a description of the general physical properties, such as the atomic weight, vapor density, etc., which are only inserted here for the sake of completeness.

\section{LIST OF REFERENCES ${ }^{1}$}

I818. Berzelius. Schweigg. J. 23, 309-344, 430-484. Discovery ; separation : character; compounds; atomic weight.

"It should be noted that I have used the abbreviation "Ann." for both the Annales de chimie et de physique, and Liebig's Annalen. Since the series number always accompanies references to the former, no ambiguity is possible. 
1826. Seebeck. Pogg. 6, I55. Electrification of vitreous selenium.

- Berzelius. Pogg. 7, 242. Purification.

- Berzelius. Pogg. 8, 21. Atomic weight.

I827. Mitscherlich and Nitzsch. Pogg. 9, 627-630. Selenic acid, and salts.

- Magnus. Pogg. 10, 49r. Solubility in sulphuric acirl.

1828. Fischer. Pogg. 12, I53-155. Solubility in sulphuric acid.

- Magnus. Pogg. 14, 328. Solubility in sulphuric acid.

1829. Fischer. Pogg. I6, I21. Solubility in sulphuric acid.

18,30. Magnus. Pogg. 20, 165-166. Separation from componinds.

I83r. Rose. Pogg. 2I, 43I. Sulphur, selenium, tellurium.

I839. Knox. Trans. Roy. Irish. Acad. 19, I49 (1843); or Phil. Mag. [3] 16, I85. Conductivity.

I840. Regnault. An11. [2] 73, 5I. Specific heat.

- Fröbel. Pogg. 49, 590-59I. Crystal form of the metallic modification.

1845. Riess. Pogg. 64, 50. Electrification of vitreous selenium.

I847. Sacc. Ann. [3] 21, I19-126. Atomic weight.

I848. Schaffgotsch. J. pr. Chem. 43, 308-309. Specific gravities.

1849. Erdmann and Marchand. J. pr. Chem. 55, 202 (1852). Atomic weight.

I85r. Hittorf. Pogg. 84, 2I4-220. Melting-point of the metallic form, $217^{\circ}$. Transformation from vitreous to metallic causes evolution of heat. Specific gravity of metallic form. Vitreous selenium a non-conductor. Metallic selenium a conductor.

1853. Schaffgotsch. Pogg. 9o, 66-82. Specific gravities.

185. Mitscherlich. Berl. Akad. 409-416, or J. pr. Chem, 66, 257-265, or Ann. [3] 46, 30I-3I3. Description of the red crystalline form, its crystallography, density, melting-point; transformation of amorphous and vitreous selenium in carbon disulphide.

1856. Regnault. Ann. [3] 46, 28I-30I, or Pögg. 98, 4I8-434. Specific heat; transformation ; general properties; heat of transition.

I857. Oppenheim. J. pr. Chem. 71, 279-282. Separation from teliurium by potassium cyanide.

- Böttger. J. pr. Chem. 7 I, 5 I2. Decomposition of selenide solutions.

1859. Dumas. Ann. [3] 55, I86-187. Atomic weight.

- Deville and Troost. C. r. 49, 239. Vapor density.

I86o. Uelsmann. Ann. II6, 122. Various compounds.

I863. Deville and Troost. C. r. 56, 89I. Vapor density.

- Werther, J. pr. Chem 88, I80-181. Spectrum.

I865. Böttger. J. pr. Chem. 94, 439-410. Separation by dissolving in sodium sulphite solution.

- Neuman1. Pogg. 126, 123. Specific heat and specific gravity of the metallic form.

- Plücker and Hittorf. Phil. Trans, 155, I-29. Spectrum.

I866. Schneider. Pogg. I28,327-334. Solubility in selenious bromide ; preparation of that substance.

1868. Bettendorf and Wiillner. Pogg. r33, 293. Specific heat of vitreous and metallic selenium. Specific gravity of the metallic form.

- Quincke. Pogg. 135,629. Capillarity constant. 
1869. Fizeau. C. r. 68, I125. Coefficient of expansion.

- Schultz-Sellack. Berl. Akad. Ber. 745, or Pogg. I39, 182. Diathermancy.

- Rathke. J. pr. Chem. 108, 235-254 and 321-356, or, somewhat condensed, Ann. 152, 181-220. Analogies between seleninm and sulphur. Various selenium compounds.

1871. Sirks. Pogg. 143, 429-439. Refraction and dispersion of amorphous selenium.

- Ditte. C. r. 73,622 . Spectrum.

1873. Petersson. B. 6, I466-1477. Separation by means of potassium cyanide.

- Salet. Ann. [4] 28, 47-49. Spectrum.

- Sale. Pr. Roy. Soc. 2I, 283-285, or Pogg. 550, 333-336. Conductivity and light effect.

- Smith. Am. J. Sci. [3] 5, 30I. Conductivity and light effect.

1874. Rosse. Phil. Mag. [4] 47, I6I. Conductivity and light effect.

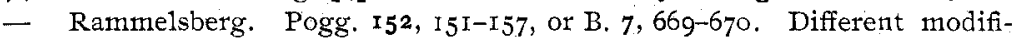
cations; crystallography; density.

- Nilson. B. 7, 1719-1721. Separation by potassium cyanide.

- Hilger. Ann. I7 I, 2I I-2I2. Solubility in sulphuric acid.

1875. Siemens. Pogg. 156, 334-335. Influence of light on conductivity ; preliminary notice.

- Adams. Pr. Roy. Soc. 23, 535-539. Conductivity and light effect.

- Siemens. Ding1. pol. J. 217,6I-63. Electrical photometer.

1876. Pettersson and Ekman. B. 9, I2IO-12I2. Atomic weight.

- Draper and Moss. Ch. N. 33, I. Conductivity and light effect.

- Moss. Ch. N. 33, 203. Effect of mercury on conductivity of selenium.

- Adams. Pr. Roy. Soc. 24, I63-164, or Pogg. I59, 629-631. Conductivity and light effect.

- Siemens. Pogg. I59, II7-I4I, or Berl. Akad. Effect of light and heat on the conductivity of selenium.

- Adams and Day. Pr. Roy. Soc. 25, II3-II7. Conductivity and light effect.

1877. Braun. Wied. 1,95 . Conductivity and light effect.

- Forssmann. Wied. 2, 512-521. Conductivity and light effect.

- Siemens. Wied, 2, 534. Conductivity and light effect.

I878. Sabine. Phil. Mag. [5] 5, 40I-415. Conductivity; effect of light and heat.

1879. Carnelley and Williams. Ch. N. 39, 286. Boiling-point.

- Cross and Higgin. J. C. S. 35, 253. Action on water.

1880. Breguet. Ann. [5] 21, 560-563. Photophone.

- Obach. Nature, 22, 496. Effect of phosphorescent light on conductivity.

- Bell. Proc. Am. Assn. Adv. Sci. 115-136, or Ann. [5] 21, 399-430. Photophone.

- Blondlot. C. r. 9I, 882. Electrical properties.

I881. Kalischer. Carl's Rep. d. Phys., 17, 563-570. Photophone without battery.

- Moser. Phil. Mag. [5] 12,212. Action between selenium and metals, etc. 
188T. Bidwell. Ch. N. 43, 105. Telephotograph.

- Mercadier. C. r. 92, 789 and I407. Photophonic receivers.

- Spring. Bull. Acad. Belg. [3] 2, 88, or CB. III, 13, I46. Coefficient of expansion.

- Bornträger. Ding1. pol. J. 242, 55. Preparation of metallic crystals by sublimation.

I882. Troost. C. r. 94, I508-1510. Boiling-point.

- Kienlen. Bull, 37, 440-443. Method of extraction.

1883. Bidwell. Phil. Mag. [5] $\mathrm{I}_{5}, 3 \mathrm{I}-35$. Conductivity and heat and light effects.

- Schuller. Wied, 18, 359. Distillation of selenium.

- Fritts. Am. J. Sci. [3] 26, 465-472. Conductivity and light effect.

I884. Husehus. Jour. Russ. phys-chem. Soc. 15, 123 and 146, or Carl's Rep. d. Phys. 20, 490-499 and 565-577. Theory of light effect.

- Brit. Assn. Rep. 440. Spectrum.

- Bidwell. Ch. N. 5I, 26I and 310 . On the resistance of sulphur and selenium cells.

- Divers and Shimosé. Ch. N. 5I, 199. Separation of selenium and tellurium.

I885. Schulze. J. pr. Chem. (2) 32, 390-407. Soluble selenium.

- Bidwell. Phil. Mag. [5] 20, I78-I9r. Conductivity and light effect.

- Bidwell. Ch. N. 52, I9I-I93. Light sensitiveness due to selenides.

- Divers and Shimosé. B. I8, I209-โ2II. Separation from tellurium by sulphuric acid.

- Morize. C. r. 100, 27I Selenium actinometer.

I886. Fabre. C. r. 103, 53-55. Heat of transformation, vitreous into metallic. See 1887 .

1887. Fabre. Ann. [6] 10, 472-550. Heat of transformation.

- Bellati and Lussana. Gazz. chim. Ital. 17, 391. JB. 207. Heat conductivity of metallic selenium increased by light.

- Kalischer. Wied. 31, IOI-I08. Electromotive force and light effect.

- Muthmanı. B. 20, 990. Soluble selenium.

1888. Righi. Wied. Beibl. I2, $68_{3}$. Electromotive force of selenium in the light.

- Uljanin. Wied. 34, 24I-273. Electromotive force of selenium in the light.

- Kalischer. Wied. 35, 397-399. On the articles of Righi and Uljanin.

1889. Righi. Wied. 36, 464-465. Reply to Kalischer.

- Korda. J. de Phys. [2] 8, 23I, or Wied. Beibl. I4, 50. Conductivity.

1890. Muthmann. Z. f. Kryst. 17,336-367. Preparation and properties of the two monoclinic red forms. Crystallography of these and of metallic selenium.

I89r. Petersen. Zeit. phys. Ch. 8, 612-6:6, Allotropic forms ; heat of transition; density.

- Bidwell. Phil. Mag. [5] 31, 250-256. Conductivity and light effect.

- Muthmann. Zeit. phys. Ch. 8, 396-397. Isomorphism with sulphur.

- Retgers. Zeit. phys. Ch. 8, 72. Isomorphism of sulphur, selenium, tellurium. 
1893. Retgers. Zeit, anorg. Ch. 3, 343. Solubility in methylene iodide.

I897. Tammann. Wied, 62, 280. Two melting-points.

I898. Klages. Chem. Ztg. 22, 449-450. (CB. II, 2, p. 253). Decomposition of selenious acid by hydrogen.

- Lenher. J. Am. C. S. 20, 555. Atomic weight.

\section{THE FORMS OF SELENIUM (IN BRIEF)}

Selenium exists in three distinct forms : nium).

I. Liquid (including vitreous, amorphous, and soluble sele-

2. Crystalline red (including perhaps two closely allied forms).

3. Crystalline gray or metallic.

I. Liquid selenium has the properties of an ordinary liquid at temperatures above $220^{\circ}$. Below that it becomes gradually more and more viscous, remains soft down to about $60^{\circ}$, and at $30^{\circ}-40^{\circ}$ gets quite hard and brittle. In this form it is ordinarily known as vitreous selenium, from its conchoidal and brilliant fracture, and it is by that name that it will be called in the following pages. Its streak is red and it yields on powdering at first a gray powder, but if rubbed up very fine this becomes red and cannot then be distinguished from the form known as red powdery, or amorphous selenium, which I shall designate by the latter name. Amorphous selenium is the state in which the element separates from solutions of selenious acid on reduction; it forms, when dry, an impalpable powder without any trace of crystallinity. When warmed to $40^{\circ}-50^{\circ}$ it darkens in color and coagulates to a soft mass, which, when cooled, becomes hard and brittle again, assuming somewhat the fracture of the vitreous form. Amorphous selenium shows all the properties of the vitreous form, making due allowance for the difference in the state of aggregation, - the only difference which separates them.

Liquid selenium, whether amorphous or vitreous, is soluble to a slight extent in carbon disulphide.

Amorphous selenium, when freshly precipitated, under certain conditions, from selenious acid solutions, is soluble in water, and in this state it is known as soluble selenium. The property is lost with lapse of time. 
2. The red crystalline form separates from solutions in carbon disulphide or may be obtained by simply allowing the amorphous or vitreous form to stand in contact with that or some other solvent at ordinary temperatures. It is probable that it has two different crystal habits, both belonging to the same system, and both soluble in carbon disulphide; there may be a slight difference of stability between these two; there are indications of an instable melting-point at about $\mathrm{I} 70^{\circ}$.

3. Gray crystalline or metallic selenium as I propose to call it, is obtained from any of the above forms at higher temperatures; in presence of certain liquids the change takes place even at ordinary temperatures. The ease with which the transformation can be effected depends upon several factors, but the same form always results. This is the stable form of selenium, at all temperatures from the ordinary temperature to the melting-

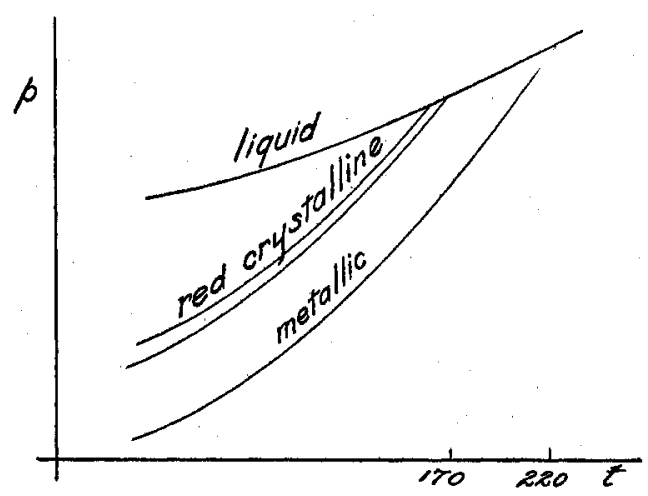

Fig. I

point, $217^{\circ} \mathrm{C}$. The other two forms are instable, the red crystalline one representing an intermediate stage between liquid and metallic selenium. It has not proved possible to effect a reverse transformation from the metallic into any other form below $217^{\circ}$, hence there is no real transition point in the physical property curves of the element.

Thus the curves representing the changes in vapor-pressure for changes in temperature should be, in their general character, somewhat as shown in the accompanying drawing (Fig. I). 


\section{PURIFICATION OF THE MATERIAL}

It was not essential for the present investigation that the last traces of impurity should be removed; hence no attempt was made to prepare absolutely pure selenium. The substance in its original form contained a considerable quantity of sulphur and a very little tellurium as impurities. The method used was to dissolve by heating in concentrated sulphuric acid, thus oxidizing the selenium to selenious acid, and then to precipitate by means of sulphur dioxide. Before precipitating, the sulphuric acid solution was diluted with water, and if necessary, filtered.

Divers and Shimose (I884) found that this method of purification was effective in removing the tellurium which does not come down under these conditions but may afterwards be precipitated by the addition of hydrochloric acid.

After reduction, vigorous shaking is necessary to bring the material together, and it should then be washed until the washings show no further acidity. If the red selenium be then separated on the filter, it will be found very difficult to dry; standing for weeks in a desiccator over sulphuric acid will not free it from water; it is therefore better to make a final washing with alcohol, then filter and dry in the air on a porous porcelain plate. One gram of the material thus purified, when dissolved in nitric acid and diluted gave no appreciable indications of the presence of tellurium, and a test for sulphur showed that this element also was present in only very small quantity.

\section{THE PROPERTIES AND TRANSFORMATIONS OF THE DIF- FERENT FORMS OF SELENIUM}

I. The vitreous modification

The form in which the element comes into commerce is the one known as vitreous, from its brilliant conchoidal fracture. The commercial material in former years consisted of medallions bearing the image of Berzelius, the discoverer of the element, but it is now almost always supplied in rods. Its color in the mass is black, but thin fragments are translucent and display a deep ruby-red color, and when very finely powdered, the 
powder is red. When heated, it begins to soften at about $50^{\circ}$, and if the heating is extremely rapid, it is possible to raise the temperature to $220^{\circ}$ withont causing any transformation into a denser form; at this temperature it is distinctly liquid, though still viscous; it does not attain a state of thin fluidity below about $250^{\circ}$. This has led to a misleading statement in many of the textbooks, the responsibility for which rests with Sacc (1847), to the effect that, while the gray crystalline or metallic variety melts sharply at $217^{\circ}$, the vitreous form only becomes really liquid at $240^{\circ}-250^{\circ}$. The fact of course is that the liquid obtained at $217^{\circ}$ is the same from whichever source, but it possesses at that temperature, a moderately high viscosity. When melted selenium is cooled down, the vitreous form is always obtained, unless the cooling is conducted very slowly, in which case it may go over to the more stable metallic form.

Berzelius ( $18 \mathrm{I} 8$ ) remarks that the vitreous form is semifluid at $100^{\circ}$, completely so a few degrees higher; probably in his experiment the transformation into the metallic form set in at about the time that the temperature had attained $100^{\circ}$; this change sets free so large a quantity of heat that the mass may very well have assumed for a few moments a state of thin fluidity.

If vitreous selenium be slowly heated and a thermometer placed in the mass, it is found (Regnault, $185^{6}$ ) that when the temperature has attained a point about $96^{\circ}-97^{\circ}$, there is a sudden rise in the temperature, amounting under favorable circumstances to as much as $150^{\circ}$; the mass becomes completely fluid and after a few moments hardens again. The substance thus formed is found, when examined, to possess quite different properties from the original vitreous selenium. This is, in fact, the gray crystalline form, appropriately called by Regnault metallic selenium.

This transformation was studied by Hittorf (I 85 I), later by Regnault and many others. Regnault's observation that the change begins at $96^{\circ}-97^{\circ}$ has led to the belief that there is something significant in these temperatures. Such is not the case. The fact is that vitreous selenium probably goes over into 
the metallic form at all temperatures under $217^{\circ}$, but the change, in the absence of solvents, does not possess a measurable velocity below about $90^{\circ}$. Indeed Regnault states that it may be kept for hours at $90^{\circ}$ without any change occurring. This is probably true, in general, when selenium is heated by itself ; nevertheless Hittorf states that the change occurs anywhere between $80^{\circ}$ and $217^{\circ}$, and Rammelsberg (I876) gives $90^{\circ}$ as the limit of stability. At $95^{\circ}$ or any higher temperature, until we approach the melting-point, the change goes on rapidly. Hittorf made some experiments to determine the point of maximum velocity, and placed it at about $125^{\circ}$.

Positive evidence was still wanting, to show whether the change was really a reversible or an irreversible one, i. e., to determine whether vitreous selenium is really unstable at all points below $2 \times 7^{\circ}$, or whether it has at lower temperatures a region of stability. The idea of a transition point has gained a hold on the minds of some, through a remarkable experiment of Lehmann; which we shall now consider. Thus Tammann (I 897) has been led to consider this an example of a substance having a second melting-point, analogous to the case of chloroform as reported

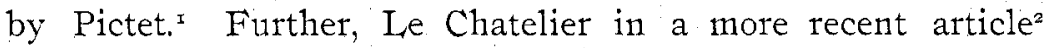
expresses himself in these words: "Selenium is only stable in the crystalline state above $60^{\circ}$ and below $214^{\circ}$. Outside of these extreme limits of temperature, the amorphous modification (vitreons, liquid) alone is stable."

The observation of Lehmann upon which these statements are based, was made with the microscope and is reported by him as follows: ${ }^{3}$

"When melted under a cover-glass, selenium appears as a clear red transparent liquid; on further warming, the liquid gets darker and black points make their appearance here and there; these increase in size and assume the aspect of spherical aggregates (sphärolithische Aggregationen) of the insoluble gray

\footnotetext{
${ }^{1}$ Zeit. phys: Chem. I6, 422 (I895).

${ }^{2}$ Comptes rendus, 129, 282 (I 899 ).

"Xolekularphysik, I, 7 I 2 .
} 
modification. ... The crystals soon fill the whole field, and, on still further heating, the mass melts to a dark, almost opaque liquid. On cooling down slowly, the spherical crystals of the gray modification appear at first, and then, as they grow steadily smaller, the color of the liquid becomes less intense, and we obtain finally the original clear red liquid. If the cooling is rapid, the crystals of the gray modification do not appear, but the liquid passes gradually from dark red to light red. The same behavior is shown on rapid warming; here also the black crystals may appear momentarily and disappear again, but sometimes the transition is direct from the red condition into the more deeply colored one. The increased absorption of light on heating and the reverse change on cooling, point to a chemical change in the liquid such that it is to be regarded at higher temperatures as partially a solution of the gray modification.

On attempting later to reproduce the above inversion (Rückgängigwerden der Entglasung) it did not prove possible to do so; perhaps because of greater or less impurity of the selenium, perhaps because the conditions were not favorable for the production of the gray (light-sensitive, less conducting) modification." All my attempts to repeat this observation of Lehmann's also failed. I have not been able to find under the microscope anything abnormal in the behavior of the element. Lehmann's observation must therefore remain for the present unexplained; possibly local heating or some other experimental irregularity may have been the cause of the appearance and subsequent disappearance at lower temperatures, of the crystals.

A better method of approaching this problem is afforded by measurements with the dilatometer, and the following section is devoted to an account of such experiments.

\section{Dilatometer Measurements}

The experiment of Lehmann, to which reference is made above, indicated the possibility of a real transition point in the change from vitreous to metallic selenium. Dilatometric measurements being the most satisfactory means of establishing such 
a point, the present study was begun with the dilatometer. The difficulties met with, which are discussed Iater on, had their source in the fact that it was necessary to work over a range of more than $200^{\circ}$, and it was not easy to find a liquid which answered the purpose. Several were tried : aniline, quinoline, glycerine, and solid and liquid paraffin.

For those determinations which were made with solid paraffin, it was necessary to surround the stem of the dilatometer with a steam jacket, and also to enclose that part of it which passed through the lower stopper of the jacket, in copper tubing, to prevent the solidification of the paraffin in the capillary.

Even when liquid paraffin is used, the steam jacket is of value because, without it, the high viscosity of the paraffin at lower temperatures renders it difficult to obtain concordant results, where the bulb is subjected to rapid changes through a wide range of temperature.

For the sunlight experiments, a bath of glycerine or highboiling paraffin was used; for the others, a bath of oil. The Reichert gas regulator proved of service in maintaining a constant temperature within a couple of degrees, when it was desired to keep the bath for some time at a fixed point. The stirring was done by means of an electric motor; what is known as the Ajax motor proved most efficient. The dilatometer tube was always sealed; hence the pressure was generally higher than one atmosphere for the upper ranges of temperature. The recorded experiments are given under their original numbers, so that the series as given here is not complete.

\section{Dilatometer Experiments}

Experiment I. Amorphous selenium in aniline. The following readings were obtained: 


\begin{tabular}{|c|c|c|c|c|c|}
\hline Temp. & Scale & Time & Temp. & Scale & Time \\
\hline $20.1^{\circ}$ & 9 & I $2: 30$ & $2 \mathrm{I}^{\circ}$ & 10.7 & $9: 25$ \\
\hline-- & 9 & I $2: 45$ & $7^{\circ}$ & 125.2 & IO : 40 \\
\hline 29.9 & 32.5 & I : I5 & - & I 23.8 & ro : 45 \\
\hline- & 32.5 & $2: 45$ & 一 & I 20.5 & Io : 52 \\
\hline 40.2 & 56.7 & $3: 20$ & - & I I 8.5 & Io $: 56$ \\
\hline- & 56.7 & $3: 50$ & 65.5 & 104.8 & II $:$ I 5 \\
\hline 49.8 & 79 & $4: 20$ & - & IO 4.3 & I I $: 35$ \\
\hline- & 79 & $4: 50$ & 一 & 104.2 & I I : 56 \\
\hline 60.1 & 103.2 & $5: 10$ & 59.9 & 90.8 & I $2:$ I 5 \\
\hline- & 103.2 & $5: 35$ & - & 90.8 & I $2: 40$ \\
\hline
\end{tabular}

The material was then slowly cooled to room temperature.

\begin{tabular}{|c|c|c|c|c|c|}
\hline $23.2^{\circ}$ & 3.2 & $2: 28$ & $7 \mathrm{I}^{\circ}$ & II 6.8 & $9: 42$ \\
\hline 23.1 & 3.0 & $2: 40$ & - & I I 7.0 & I I : \\
\hline 22.5 & 2.0 & $4: 00$ & 80.2 & 138.3 & I I : I7 \\
\hline 69.6 & I I 3.6 & $4: I 5$ & 一 & 138.3 & I I $: 3$ I \\
\hline- & I I 3.7 & $4: 33$ & 97 & $177 \cdot 3$ & I $2: 22$ \\
\hline 70.8 & I I 6.5 & $4: 36$ & - & $177 \cdot 3$ & $12: 37$ \\
\hline- & I 16.3 & $5: 00$ & & & \\
\hline
\end{tabular}

The first group of values shows that amorphous selenium in aniline shows no immediate change in volume when heated to $60^{\circ}$. (Later experiments have shown that there is a change when amorphous selenium remains in contact with aniline, even at ordinary temperatures; but this goes on comparatively slowly). The second group shows that at $70^{\circ}$ a change sets in, which continues, though slowly, when the temperature is lowered to $65^{\circ}$; the apparent checking of the reaction at $60^{\circ}$ was probably due to the fact that all the selenium was already transformed. It is important to notice that there was no sign of a tendency to return to the original volume when the temperature was maintained for twenty-five minutes at $60^{\circ}$ and then slowly lowered to the temperature of the room. The remaining values show that no further change goes on up to $97^{\circ}$; the slight variations in tenths of a millimeter on the scale are not to be regarded as significant. In this experiment it was noticed that at $40^{\circ}$ the selenium had shrunk together to about half of its original volume, and when the temperature had reached $50^{\circ}$ it had become almost black and formed a small mass in the bottom of the bulb. 
Experiment 4. Amorphous selenium in aniline, using a larger quantity of selenium than in exp. I. In this experiment, as in many which follow, the rise in temperature of the bath was slow and continuous, and readings were taken at intervals; not all of these are recorded here, but enough to make it possible to reconstruct the expansion curve; where any change was perceptible, the temperature was held constant for a time at that point. The selenium used in this experiment was first heated to $50^{\circ}$ to facilitate the liberation of air bubbles which adhere to the powder.

\begin{tabular}{|c|c|c|c|c|c|}
\hline Temp. & Scale & Time & Temp. & Scale & Time \\
\hline $19.8^{\circ}$ & 10.3 & $12: 20$ & - & 90.3 & $3: 03$ \\
\hline $60 . \mathrm{I}$ & 97.0 & I $2: 40$ & Trar & erred to & d water \\
\hline- & 97.2 & I $2: 43$ & 20.2 & 3 & $3: 09$ \\
\hline 60 & 91 & $3: 00$ & - & 3 & $3: 40$ \\
\hline
\end{tabular}

After standing over night

\begin{tabular}{|c|c|c|c|c|c|}
\hline$\overline{17} 7^{\circ}$ & -2 & $9: 35$ & $66^{\circ}$ & 89. & $12: 05$ \\
\hline 28 & I 8 & $9: 50$ & - & 64.5 & I $2: 50$ \\
\hline 35 & 35 & $10: 02$ & - & $6 I$ & $3: 00$ \\
\hline 43 & 52 & $10:$ I 5 & 69 & 67 & $3: 05$ \\
\hline 48 & 63 & I I : 22 & 79 & 87.5 & $3: 23$ \\
\hline 60 & 87.5 & I I : 48 & 90 & 109.5 & $3: 45$ \\
\hline 66 & 95.5 & I I $: 58$ & 100 & I 29 & $4:$ I 5 \\
\hline
\end{tabular}

The dilatometer was then cooled down, and in a subsequent experiment lasting about four hours the temperature was slowly raised from $72^{\circ}$ to $202^{\circ}$ without any irregularity in the expansion curve being observed.

In experiment 4 , the contraction took place in two different stages separated by a period of cooling and then a slow rise in which the temperature was maintained for one and one-half hours between $43^{\circ}$ and $60^{\circ}$ without any return toward the original readings. This confirms the evidence of exp. I, showing that when both forms of the substance are present, the change is still only capable of going one way, i. e., is irreversible. In a later experiment this dilatometer was heated in direct sunlight during forty-five minutes from I I $3^{\circ}$ to $162^{\circ}$; the readings 
give no indication of any change in the selenium. It may be as well to state here what is later established, that the denser form obtained in all of these dilatometric experiments is metallic selenium of density 4.8 .

It was desirable after completing these experiments to heat the dilatometer up to $220^{\circ}$ in order to transform the selenium again into the liquid modification, without being under the necessity of removing it from the bulb. It did not prove practicable to do so in aniline on account of the evolution of gas, which begins in that liquid at temperatures varying from $\mathrm{I} 60^{\circ}$ upwards, according to the pressure within the tube. Aniline was therefore abandoned, and a few experiments were tried with glycerine; the same difficulty was encountered with this liquid too; nevertheless several sets of observations were made, up to about $200^{\circ}$, with the result that the transformation of vitreous selenium was found to begin at about $75^{\circ}$, no further change being observable up to $200^{\circ}$, nor was there any sign of a reverse transformation when the tube stood at $25^{\circ}$. The experiments of Siemens and others on the conductivity of selenium indicated the possibility of some change taking place in sunlight at $160^{\circ}$ or above, but although the tube which contained metallic selenium was kept for half an hour under a burning-glass, in a bath whose temperature varied between $I 5^{\circ}$ and $I 72^{\circ}$, no change was found to occur.

Some experiments were then made in quinoline. Starting with metallic sèlenium, the dilatometer was heated in the dark for five hours between $154^{\circ}$ and $196^{\circ}$ without any indication of a change at any point. Subsequent heating for three hours between $150^{\circ}$ and $200^{\circ}$ only confirmed this result. The tube was then brought into direct sunlight, placed under a burning-glass, and heated, on different days, for one and one-half hours between $150^{\circ}$ and $180^{\circ}$, for one and one-half hours from $190^{\circ}$ to $195^{\circ}$, and for one-half hour from $198^{\circ}$ to $201^{\circ}$; the readings are, within the limits of experimental error, identical with the original observations when the heating was carried on in the dark. These observations make it extremely improbable that metallic 
selenium suffers any change either in the dark or in direct surlight, when heated to temperatures between $150^{\circ}$ and $200^{\circ}$. It does not of necessity follow that the element will behave in the same way when heated in a liquid capable of dissolving it, as it will when heated by itself; on the other hand, the probability is that any change which goes on in the substance taken by itself, which leads to the production of a more stable form, will take place only the more readily in presence of a solvent. Thus, it will be shown later on that amorphous selenium, which is capable of existing by itself for an indefinite time without change, at ordinary temperatures, goes over rapidly, in the presence of pyridine and certain other liquids, to the metallic form.

The same difficulties which had been met with in working with aniline and glycerine were once more encountered with quinoline when the temperature was raised above $200^{\circ}$. It was supposed at first that all of these reactions were with the liquids themselves, but it seems more probable from later observations that the difficulty is due to small quantities of water which adhere to the selenium from the method of purification. The dilatometers when opened always had the odor of selenium hydride. Meanwhile it had been found that solid paraffin promised to give better results, and this material was then employed for several sets of observations. It was thus rendered possible to work freely between $20^{\circ}$ and $230^{\circ}$, although the results of successive transformations into the metallic form did not always lead back exactly to the same reading, on account of the gradual accumulation, in the selenium, of gas bubbles, which, under the prevailing high pressures, did not free themselves from the mass. This difficulty was obviated later by opening the tube from time to time to let the bubbles escape.

Experiment 23. Metallic selenium heated in paraffin from $60^{\circ}$ to $210^{\circ}$ shows no irregularity. When the temperature is raised to about $218^{\circ}$, the selenium begins to melt and expands; at $220^{\circ}$ the melting was complete in half an hour, and on cooling, the vitreous form was produced. The readings are as follows: 


\begin{tabular}{c|c|c}
\hline Temp. & Scale & Time \\
\hline $60^{\circ}$ & 30 & I I : 55 \\
I 72 & 257 & I $2:$ IO \\
200 & 3 I 5 & \\
210 & 336 & \\
218 & 360 & I2 : I5 (fusion begun) \\
222 & 412.5 & I 2: 49 (fusion complete)
\end{tabular}

the tube was then cooled rapidly

\begin{tabular}{l|l|l}
$57.5^{\circ}$ & 57 & $12: 55$
\end{tabular}

The dilatometer was then placed in a bath at $160^{\circ}$, whose temperature was rapidly rising. The level in the capillary rose at first, then rapidly fell, showing a sudden transformation from the vitreous to the metallic modification. The tube then stood in direct sunlight for an hour, at about $200^{\circ}$. At the end of the time, the reading was 3 II, almost identical with the above. Thereupon the temperature was raised to about $228^{\circ}$, and the material completely fused, after which the bath temperature was brought down to $200^{\circ}$, in order to determine what change takes place when melted selenium is maintained at that temperature. The readings are as follows:

\begin{tabular}{l|l|l|l|l|l}
\hline Temp. & Scale & Time & Temp. & Scale & Time \\
\hline $225^{\circ}$ & 418 & $3: 42$ & $200^{\circ}$ & 351 & $4: 24$ \\
I99 & 367 & $3: 45$ & - & 344 & $4: 33$ \\
I99 & 363 & & - & 339 & $4: 40$ \\
I98 & 359 & $3: 47$ & - & 335 & $4: 48$ \\
I98 & 357.5 & $3: 49$ & - & 330 & $4: 55$ \\
I98 & 357.5 & $3: 52$ & - & 325 & $5: 03$ \\
I97.5 & 356 & $4: 01$ & - & 322 & $5: 15$ \\
I99 & 356.5 & $4: 10$ & - & 320 & $5: 25$ \\
I99.5 & 355.5 & $4: 15$ & - & 320 & $5: 36$ \\
200 & 353.5 & $4: 20$ & - & 319 & $5: 46$
\end{tabular}

The dilatometer was then cooled to $65^{\circ}$ where the scale reading was 30 . This reading, like the final reading at $200^{\circ}$ is somewhat higher than that previously obtained. A few small bubbles of gas were observed in the bulb at the 
end of the experiment and it is to them; no doubt, that the variations are to be attributed. This experiment in itself would not be conclusive without the confirmation of later observations; the values are given in detail to indicate the rate at which the change goes on at $200^{\circ}$. The falling level in the first readings at $199^{\circ}$ is not due to a change in the selenitum, but to the lag of the instrument which does not adjust itself at once to the changed bath temperature; a closer inspection shows that the transformation of the selenium did not set in until about half an hour later and was complete about an hour after it commenced. The rate is at first very slow, then increases and remains almost constant until near the end, when it is much retarded.

Experiment 24. The same dilatometer was again heated slowly up to $2 \mathrm{I} 7^{\circ}$, the following readings being obtained:

\begin{tabular}{c|c|c|c|c|c}
\hline \hline Temp. & Scale & Time & Temp. & Scale & Time \\
\hline I I $7^{\circ}$ & I32 & $2: 56$ & I $60^{\circ}$ & 225 & $3: 24$ \\
I 30 & I61 & $3: 02$ & 172 & 250 & $3: 39$ \\
I 40 & I 82 & $3:$ I4 & I 82 & 27 I & $3: 49$ \\
I 50 & 203 & $3:$ I & 201 & 3 I & $4:$ I
\end{tabular}

The tube was then cooled down:

\begin{tabular}{r|r|r|}
$169^{\circ}$ & 248 & $4: 27$ \\
155 & 219 \\
120 & 145 & $4: 32$ \\
152
\end{tabular}

then heated to $225^{\circ}$ to effect fusion, after which the following readings were obtained on cooling down:

\begin{tabular}{|c|c|c|c|c|c|}
\hline $225^{\circ}$ & 415 & $5: 37$ & $165^{\circ}$ & 290 & $5: 57$ \\
\hline 185 & 336 & $5: 4 \mathrm{I}$ & I $5 \circ$ & 257 & $6: 01$ \\
\hline 一 & 332 & $5: 42$ & I 30 & 212 & $6:$ I 2 \\
\hline - & 332 & $5: 50$ & 69 & 82 & $6: 18$ \\
\hline 180 & 322 & $5: 52$ & & & \\
\hline
\end{tabular}

This shows that melted selenium in paraffin may be cooled down quite slowly without any transformation taking place, for the last of the above readings agrees with that found for the vitreous form in the preceding experiment where the bulb was cooled at once from $220^{\circ}$ to $57^{\circ}$. In order that the paraffin might not solidify, the tube was placed over night in water 
which varied in temperature from $60^{\circ}$ to $75^{\circ}$; on the following morning, a reading was taken at $74^{\circ}$ and the level was. found to be 78 , showing that the selenium had suffered contraction but had not gone over entirely to the metallic form. On then raising the temperature, the following readings were made :

\begin{tabular}{|c|c|c|c|c|c|}
\hline Temp. & Scale & Time & 'Temp. & Scale & Time \\
\hline $74^{\circ}$ & 78 & IO $: 5^{\circ}$ & I I I ${ }^{\circ}$ & I 27 & I0 : 30 \\
\hline 85 & IOO & I I : O2 & I I I .5 & I 25 & I I : 50 \\
\hline 90 & 108 & I I : ${ }_{5}$ & 148 & I 99 & I $2: 09$ \\
\hline 95 & I I 8 & I I : O9 & 200 & 309 & I $2: 33$ \\
\hline 105 & I 32 & I I : I9 & I 52 & 205 & I $2: 49$ \\
\hline 109 & I3 I & I I : 26 & & & \\
\hline
\end{tabular}

These observations were made in diffused daylight. The experiment still further confirms the statement that metallic selenium undergoes no change in being heated to $200^{\circ}$ and that when the temperature is brought back to $150^{\circ}$ the reading accords with that obtained with rising temperature.

The indications of a partial change at about $70^{\circ}$ followed by no further contraction up to $105^{\circ}$ are of interest, and a further experiment was undertaken later on in the hope of being able to repeat these observations. The following is the experiment in question:

Experiment 71. Selenium in solid paraffin. During three hours the temperature was slowly raised from $55^{\circ}$ to $97^{\circ}$ without any indication of a change; at this point contraction began; but the apparatus being left to itself, the temperature gradually fell during the succeeding four hours, to $73^{\circ}$; the change had then proceeded to a considerable extent; further heating at higher temperatures brought out the fact that below $90^{\circ}$ the change, even when it has commenced, goes on very slowlyat $80^{\circ}$ it amounted to about three scale divisions in an hour, where the total contraction involved nearly 80 scale divisions but the drop was continuous and reached a limit after about fourteen hours' heating at temperatures between $80^{\circ}$ and $90^{\circ}$. This experiment comes in a later class than the preceding, and was made with a weighed quantity of selenium and a dilatometer whose capillary arm had been previously calibrated. This method of procedure is much to be recommended for cases like 
the present, since it makes it possible to estimate at any moment, approximately, the density of the material studied.

The final density of the selenium was found in this way to be 4.83 . The extreme slowness with which the change goes on at $80^{\circ}$ suggests that the observations of exp. 24 may have no special significance at all; the change was probably incomplete and did not proceed tapidly to an end until the temperature was raised above $100^{\circ}$.

On the other hand, the existence of red crystalline forms of selenium, which, according to Muthmann, go over to metallic selenium at $110^{\circ}-120^{\circ}$, and which have a density of about 4.5 , points to the possibility of the occurrence here, exceptionally, of such a form; in that case exp. 7 I simply failed to reproduce the red form. It should be said further, that no indication whatever of a change of vitreous selenium into the red crystalline modification was observed in any of the other dilatometer experiments, although such a change is known to go on superficially when vitreous selenium is brought into carbon disulphide at ordinary temperatures.

The following experiments were made with liquid paraffin, unless otherwise stated:

Experiment 26. This determination was made as a further study of the density relations of the form of selenium which is produced when the melted element is cooled to $200^{\circ}$ and maintained at that temperature until no further change of volume is observed. A dilatometer containing vitreous selenium was placed in a bath at about $I 50^{\circ}$; at this temperature the change is immediate and gives rise, as is well known, to the ordinary metallic selenium. The experimental data are as follows:

\begin{tabular}{|c|c|c|c|c|c|}
\hline Temp. & Scale & Time & Temp. & Scale & Time \\
\hline I $55^{\circ}$ & 260 & I $2:$ I 2 & $219^{\circ}$ & $53 \mathrm{I}$ & [ $2: 47$ \\
\hline 160 & 273 & I $2:$ I 4 & 200 & 478 & I $2: 54$ \\
\hline I 78 & 323 & $12: 20$ & - & 468 & I $2: 56$ \\
\hline I 98 & 380 & I $2: 25$ & 202 & 461 & I : 06 \\
\hline 210 & 413 & $12: 30$ & 200 & $45^{\circ}$ & $I: I I$ \\
\hline 218 & 440 & $12: 33$ & - & 444 & I : I 3 \\
\hline 220 & 460 & I $2: 35$ & - & $43^{8}$ & I : 15 \\
\hline 22 I & 530 & $12: 43$ & & & \\
\hline
\end{tabular}


At this point the temperature was allowed to drop for a few moments to $182^{\circ}$; it was raised again at once:

\begin{tabular}{l|l|l}
\hline $185^{\circ}$ & I : 25 \\
198 & 370 & $1: 31$ \\
201 & 386 & I : 32 \\
196 & 393 & $2: 06$
\end{tabular}

The material was then heated again to fusion, and cooled to $200^{\circ}$ :

\begin{tabular}{c|c|c|c|c|c}
\hline \hline $2 \mathrm{OI}^{\circ}$ & 500 & $3: 10$ & $200^{\circ}$ & 443 & $3: 49$ \\
$\mathrm{I} 99$ & 490 & $3: \mathrm{II}$ & 200.5 & 430 & $3: 56$ \\
$\mathrm{I98}$ & 485 & $3: \mathrm{I} 3$ & - & $4 \mathrm{I} 8$ & $4: \mathrm{II}$ \\
$\mathrm{I99}$ & 485 & $3: 17$ & 198 & 398 & $4: 17$ \\
- & 485 & $3: 20$ & - & 395 & $4: 24$ \\
200 & 479 & $3: 28$ & 197 & 389 & $4: 44$ \\
- & 469 & $3: 35$ & 199 & 393 & $4: 54$ \\
- & $46 \mathrm{I}$ & $3: 39$ & & &
\end{tabular}

This experiment shows clearly that the form produced at $200^{\circ}$ is identical with the original metallic selenium. The slight difference in the readings at $200^{\circ}$ before and after fusion, is negligible in comparison with the total change of level involved in the transformation. The heating at $220^{\circ}$ to effect fusion was prolonged until there was little or no further change during several minutes, since it was plainly desirable to have the mass of selenium free from crystals of the metallic form; on the other hand, there was no object in refining too far upon this point, since we may say certainly that in the cooling dow 11 from $220^{\circ}$ to $200^{\circ}$ there would always be a small quantity of material deposited from the solution, either in the form of metallic crystals, or perhaps in some other modification if such were capable of existence at that temperature.

Experiment 28. This experiment, which was made with the dilatometer used in exp. 27 , was undertaken to determine whether or not there are two substances in the melt when selenium is brought to complete fusion and then allowed to go over partially at $200^{\circ}$. If two forms are present in the liquid state, forming but one phase, then the melting-point will be lowered, and in consequence, at temperatures below but very 
near $217^{\circ}$, any of the solid form present will melt and the dilatometer level will rise; if such is not the case, it will continue to fall. The readings were as follows:

\begin{tabular}{|c|c|c|c|c|c|}
\hline Temp. & Scale & Time & Temp. & Scale & Time \\
\hline $80^{\circ}$ & 44 & $9: 47$ & $221^{\circ}$ & $55^{8}$ & I $2:$ OI \\
\hline 100 & 92 & $9: 54$ & 200 & 497 & I $2: 06$ \\
\hline 190 & 350 & $10: 32$ & 201 & 459 & I $2: 39$ \\
\hline 207 & 398 & $10: 50$ & 199.5 & 447 & I $2: 48$ \\
\hline 218 & 433 & I I : O2 & 214 & 483 & I $2: 54$ \\
\hline 220 & 530 & I I : 29 & 2 I 5 & 478 & I:08 \\
\hline- & 553 & I I : 53 & 214.5 & 474 & I: : I 5 \\
\hline
\end{tabular}

It is plain from these figures that at $2 \mathrm{I} 5^{\circ}$, under the conditions of the experiment, the contraction continued. The recorded temperatures are uncorrected; on comparing the thermometer used with a standard thermometer calibrated at the Reichsanstalt in Berlin, it was found that the one used in these experiments registered $3^{\circ}$ too low at $2 I 5^{\circ}$. Since selenium expands on melting, it follows from the theorem of Le Chatelier that the meltingpoint will be raised by increased pressure; but as the prevailing pressure within the tube was, in this experiment, not above 6 to 8 atmospheres, it is improbable that this would very sensibly affect the melting-point. Reicher ${ }^{\mathrm{I}}$ found that an increase of 4 atmospheres only raised the inversion point for rhombic and monoclinic sulphur by about $0.2^{\circ}$, whereas the melting-points of various substances - water, naphthalene, etc. - are even less sensitive to pressure changes. ${ }^{2}$ It seems most likely in this case that the recorded value $2 \mathrm{I} 7^{\circ}$ is somewhat low and that the melting-point of gray selenium should be placed nearer $220^{\circ}$. At any rate, the experiment shows that liquid selenium continues to go over into the solid form at temperatures lying very near the melting-point, and this renders the existence of a second form in the liquid phase most improbable.

Experiment 29. This determination was conducted with the same dilatometer that was used in exp. 28. Starting from vitreous selenium, the following readings were made:

${ }^{2}$ Recueil Trav. Pays-Bas, 2, 262 (i 884 ).

' Ostwald : Lehrb. I, Ior 3. 


\begin{tabular}{r|r|l||l|l|l}
\hline Temp. & Scale & Time & Temp. & Scale & Time \\
\hline $55^{\circ}$ & 60 & $2: 38$ & I9I & 418 & $2: 491 / 2$ \\
80 & I25 & $2: 4 \mathrm{I}$ & I97 & 419 & $2: 50$ \\
I32 & 270 & $2: 45$ & 202 & 407 & $2: 54$ \\
158 & 350 & $2: 47$ & 204 & 406 & $3: 06$ \\
I72 & 385 & $2: 48$ & 201 & 396 & $3: 57$ \\
I85 & 410 & $2: 49$ & I95 & 380 & $5: 20$
\end{tabular}

This experiment shows that it is sometimes possible, by rapidly raising the temperature of vitreous selenium, to heat it to aboitt $185^{\circ}$ before the transformation begins; but a comparison with the readings in exp. 26 shows that the form produced in this way at $200^{\circ}$ is the same as that obtained by any of the other methods used; and furthermore, its density is not changed by heating for two and one-half hours at about $200^{\circ}$.

Experiment 30. A continuation of exp. 29. Starting from vitreous selenium, the temperature was rapidly raised, and in this case attained almost $175^{\circ}$ before the transformation began. The subsequent readings are as follows:

\begin{tabular}{c|c|c}
\hline Temp. & Scale & Time \\
\hline I $75^{\circ}$ & 390 & $9: 39$ \\
186 & 397 & $9: 40$ \\
195 & 395 & $9: 4 \mathrm{I}$ \\
203 & 405 & $9: 47$ \\
I99 & 393 & I I $: 20$
\end{tabular}

This confirms the results of exp. 29.

The tube was next heated to $225^{\circ}$ to effect fusion, and then cooled to $I 25^{\circ}$ to observe the nature of the transformation at that point. The readings are:

\begin{tabular}{|c|c|c|c|c|c|}
\hline Temp. & Scale & Time & Ternp. & Scale & Time \\
\hline $232^{\circ}$ & 560 & I I $: 45$ & I $76^{\circ}$ & 310 & I $2: 43$ \\
\hline I 25 & 265 & I $2: 03$ & - & $3 \mathrm{II}$ & $I: O I$ \\
\hline I 27 & $23 \mathrm{I}$ & I $2:$ I 6 & 198 & 377 & $I: 30$ \\
\hline- & 177 & I $2: 32$ & 206 & 399 & I $: 50$ \\
\hline - & 177 & I $2: 37$ & & & \\
\hline
\end{tabular}


The transformation at $125^{\circ}$ brings the dilatometer back to a reading almost identical with that obtained by interpolation from the results of exp. 28, where the dilatometer contained selenium which had been changed over at $200^{\circ}$ and then cooled down.

In the experiments which follow, special care was taken to eliminate water from the system. The paraffin used in all these later experiments was dried by sodium. For drying selenium which has been precipitated out of an aqueous solution of selenious acid, it is by no means sufficient to heat it for an hour or two at $\mathrm{r} 2 \mathrm{O}^{\circ}$, although by this means it goes over to the metallic form, and one would suppose that such a change would belikely to set free all the moisture present; on fusing such a preparation in a tube, however, a very considerable quantity of water is still given off. The material here used was dried by heating to $230^{\circ}$ for some time, in an exhausted $\mathrm{A}$-shaped tube, containing sulphuric acid in the other arm. By observing these precautions and by occasionally opening the dilatometer tube to permit the escape of the small bubbles which had developed in the bulb, it was possible to get very concordant results. These experiments confirm the earlier ones.

Experiment 32. New dilatometer ${ }^{x}$ Starting from metallic selenium, the following observations were made:

\begin{tabular}{r|r|l|l|l|l}
\hline Temp. & Scale & Time & Temp. & Scale & Time \\
\hline $84^{\circ}$ & 5 I & & $2235^{\circ}$ & 562 & $3: 32$ \\
I53 & 243 & & 200 & 477 & $3: 36$ \\
I96 & 36 I & $2: 5$ I & I92 & 428 & $3: 46$ \\
204 & 386 & $3: 06$ & I98 & 374 & $3: 59$ \\
219 & 430 & $3:$ I 2 & I96 & 362 & $4:$ I I \\
228 & 525 & 3: I9 & & &
\end{tabular}

Here the last reading at $196^{\circ}$ accords almost exactly with the first. The material was again fused and then rapidly cooled; on heating up again, the transformation began at about $130^{\circ}$ and gave, after coming to rest at $\mathrm{I} 9 \mathrm{I}^{\circ}$, a reading of 355 , which accords very closely with the above value of 362 at $196^{\circ}$.

${ }^{1}$ In the later experiments a side tube was set on, at an angle, to the bulb of the dilatometer. This facilitates the filling and can be sealed off afterwards. 
Experiment 36 was made with a new dilatometer. The level at $199^{\circ}$ corresponding to the more dense form, was $32 \mathrm{I}$ on the scale. After fusion and cooling, it was placed in a bath at $200^{\circ}$; the transformation took place very rapidly and the level came to 322 at $199^{\circ}$, from which there was no further change during five minutes. The material was again fused and cooled, and then placed in a bath of boiling water until the change was almost completed; it was then replaced in a $200^{\circ}$ bath where it gave a reading of 314 at $197^{\circ}$. The selenium was again fused and cooled down. This time it was placed in a cold bath whose temperature was then rapidly raised - this being the method by which Siemens prepared his light-sensitive selenium cells. The change began at about $120^{\circ}$ and the temperature, after reaching $200^{\circ}$, was maintained for some time at that point; the dilatometer gave a final reading of $32 \mathrm{I}$ at $200^{\circ}$. On being transferred to a bath of boiling water, it gave a reading of $3^{6}$ at $99^{\circ}$. The material was once more fused and then placed directly in the water-bath; the final reading was 44 and as the change proceeds very slowly toward the end, this may reasonably be taken as a trifle too high. Finally the temperature was raised to $200^{\circ}$ and then lowered to $80^{\circ}$; all the readings so obtained were found to lie along one line and there was nowhere any sign of a change. This line cuts $100^{\circ}$ at a little above 40 , and $200^{\circ}$ a little above 320 .

In order to make sure that the denser form which plays so important a part in these dilatometer experiments was really metallic selenium, the material was removed from this last bulb and its specific gravity determined. The value found was 4.77 .

Experiment 36 shows that metailic selenium is the only form which results from the transformation of the vitreous modification, whether at $100^{\circ}$ or in a bath whose temperature is rapidly raised to $200^{\circ}$. The readings obtained at $200^{\circ}$ are the same in each of these two cases, and are identical with that obtained by holding fused selenium at $200^{\circ}$ until the transformation is complete.

Experiment 4r. This was a further attempt to get some 
indication of a reverse change from the gray metallic into a less dense form, below $100^{\circ}$. Starting from vitreous selenium, the following readings were taken:

\begin{tabular}{|c|c|c|c|c|c|}
\hline Temp. & Scale & Time & Temp. & Scale & Time \\
\hline $59^{\circ}$ & I I 4 & I I : I 5 & $80^{\circ}$ & I 34 & I : 20 \\
\hline 62 & I I 8 & I $\mathbf{I}:$ I 8 & $8 \mathrm{I}$ & 96 & $2: 30$ \\
\hline 68 & 130 & I I : 27 & - & 66 & $4: 06$ \\
\hline 74 & I 41 & I I $: 40$ & 70 & 47 & $4: I 5$ \\
\hline 81 & 154 & I2: I6 & 69.5 & 45 & $4: 35$ \\
\hline 83 & 157 & I $2: 25$ & $9^{8}$ & 92 & $4: 45$ \\
\hline 82 & I 53 & I $2: 35$ & - & 84 & $5: 05$ \\
\hline
\end{tabular}

The experiment shows that, when the change has proceeded some distance at $8 \mathrm{I}^{\circ}$, and the temperature is lowered to $70^{\circ}$, there is no sign of a recovery during twenty minntes, although the last two readings show that the transformation was not complete, i. e., that two forms were present.

Experiment 43. Confirmatory of exp. 4I. This determination, which was carried on in a dilatometer filled with quinoline, yielded the following readings :

\begin{tabular}{c|c|c|c|c|c}
\hline Temp. & Scale & Time & Temp. & Scale & Time \\
\hline 8 I $^{\circ}$ & I I 2 & $2: 08$ & $70^{\circ}$ & 42 & $4: 15$ \\
- & 93.5 & $2:$ I 5 & 69.5 & $4 \mathrm{I}$ & $4: 35$ \\
- & 74 & $2: 40$ & 98 & $7 \mathrm{I}$ & $4: 48$ \\
- & 56 & $3: 36$ & - & 66 & $5: 05$ \\
- & 52.5 & $4: 06$ & & &
\end{tabular}

Experiment 45. Carried on with the same dilatometer that was used in exp. 4r. Starting from vitreous selenium these readings were made :

\begin{tabular}{|c|c|c|c|c|c|}
\hline Temp. & Scale & Time & Temp. & Scale & Time \\
\hline $65^{\circ}$ & I 27 & $12: 32$ & 78.5 & 150.5 & $2: 03$ \\
\hline 71.5 & I39 & I : IO & 80 & 152 & $2: 16$ \\
\hline 74 & I 43 & $I: 32$ & 81.5 & I 52 & $2: 34$ \\
\hline 77 & I 48.5 & $I: 5 I$ & 78 & I39 & $3: 07$ \\
\hline
\end{tabular}


showing that the transformation began at abont $80^{\circ}$ in this case. The temperature was then raised -

\begin{tabular}{l|l|l}
\hline $107^{\circ}$ & 178 & $3: 36$ \\
125 & 150 & $3: 38$ \\
130 & 122 & $3: 39$ \\
156 & 158 &
\end{tabular}

Then the dilatometer was placed in the cooler bath -

\begin{tabular}{l|l|l}
\hline $67.5^{\circ}$ & I9 & $3: 5$ I \\
- & I & $4: 15$
\end{tabular}

The dilatometer then stood over night, and registered on the following day -

$-\frac{\text { Temp. }}{58.5^{\circ}} \mid-\frac{\text { Scale }}{0}-1-$

Four days later the level was again taken

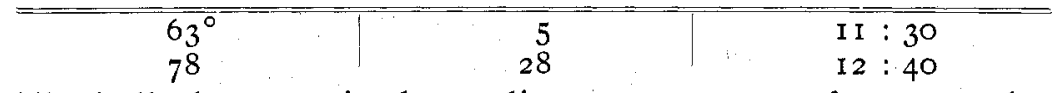

The bulb then remained at ordinary temperatures for two weeks, sometimes standing for half a day in direct sunlight. At the end of that time, a reading was again taken and gave

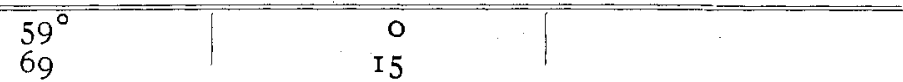

and after standing in sunlight for a few hours more, it gave on the following day

$$
70^{\circ}=7
$$

Two months later a reading was again taken, and gave at

$$
63^{\circ}-4
$$

which shows that no change had taken place.

This experiment illustrates the complete stability of metallic selenium at ordinary temperatures and up to $60^{\circ}$, whether it be kept in diffused daylight or in direct sunlight.

When selenium is heated by itself to $100^{\circ}$ it does notalways go over entirely to the metallic form. Petersen (189I) found 
that specimens of selenium which were transformed from the vitreous into the metallic form, at whatever temperature, always contained more or less of the original material. This is illustrated by the following experiment:

Experiment 46. A quantity of vitreous selenium was heated for half an hour in a water-bath, and was then placed in a dilatometer with quinoline. The following are the readings:

\begin{tabular}{c|c|c}
\hline \hline Temp. & Scale & Time \\
\hline $74^{\circ}$ & 103 & $\mathrm{I}: 32$ \\
80 & 92 & $2: 16$ \\
78 & 78 & $3: 00$ \\
73 & 70 & $3: 2 \mathrm{I}$ \\
67.5 & 63 & $3: 45$
\end{tabular}

The dilatometer was, later on, heated for five hours between $45^{\circ}$ and $60^{\circ}$ and showed no signs of a reverse transformation, although raising the temperature afterwards to $80^{\circ}$ showed that the transformation had not been entirely completed.

When vitreous selenium is placed in a dilatometer with water, the transformation begins at about $80^{\circ}$ and proceeds slowly but uninterruptedly to an end, as shown by the following experiment :

Experiment 69. 3.06 grams of vitreous selenium were placed in a dilatometer provided with a capillary arm previously calibrated. The following readings were made :

\begin{tabular}{l|l|l}
\hline Temp. & Scale & Time \\
\hline $64^{\circ}$ & 89 & I I :44 \\
$7 \mathrm{I}$ & 98 & I $2:$ I4 \\
77 & I06 & I $: 30$ \\
79 & I08.5 & I $2: 35$ \\
81 & III & I $2: 40$
\end{tabular}

A slight transformation took place at this last temperature and the experiment was continued on the following day: 


\begin{tabular}{|c|c|c|c|c|c|}
\hline Temp. & Scale & Time & Temp. & Scale & Time \\
\hline $67^{\circ}$ & 86 & & $80^{\circ}$ & 65.5 & I $2: 06$ \\
\hline 82 & 102.5 & & 79 & 58.5 & I $2: 40$ \\
\hline 85.5 & 105 & I I $: 05$ & 8 I & 42.5 & $2: 15$ \\
\hline 84 & 87 & I I $: 28$ & 80 & 36 & $4: 20$ \\
\hline 83 & 81 & I I : 36 & & & \\
\hline
\end{tabular}

and on the following day :

\begin{tabular}{c|c|c}
\hline Temp. & Scale & Time \\
\hline $79^{\circ}$ & 27 & I I : 20 \\
80 & 26 & I $2: 30$ \\
7 & 24 & $3: 30$ \\
77 & $2 \mathrm{I}:$ I0
\end{tabular}

The transformation may be taken as complete.

Calculating the change in density from the difference between the original and final readings at $77^{\circ}$ and assuming the density of vitreous selenium to be $4 \cdot 3$, we find for the density of the metallic form by this experiment $4 \cdot 77$. The determination shows that no other forms make their appearance here but the two mentioned.

In another experiment, also carried on in water, a quantity of selenium was heated in a water-bath for one and one-half hours, after which no further change of volume could be noted. The mass had the familiar steel gray color. On raising the temperature to $I 0^{\circ}$ no change took place. Some of it was then taken out, and placed in a dilatometer containing aniline, and heated during one and one-half hours to about $I 50^{\circ}$. This also brought about no further change, showing that in water as well as in other liquids, it is the metallic form which always results from a transformation of the vitreous modification no matter at what temperature this transformation is effected.

\section{Conclusions from dilatometric experiments}

It may seem that the experiments with the dilatometer have been needlessly multiplied. This repetition is due in part to the fact that the method of working was at first very imperfect, but 
mainly to the fact that the evidence to be obtained from them is both positive and negative. There is to be found in many of the textbooks a description of the gray form of selenium obtained by heating the vitreous modification to $100^{\circ}$, which separates this as a distinct modification from the black crystals obtained in other ways, and these experiments were begun with the expectation of finding two such distinct forms with a real transition point. It will be seen, however, that the evidence is all against the existence of any stable form except the one having a density of 4.8 and the multiplicity of the experiments only serves to render that evidence mote conclusive. When selenium is heated in liquids in which it is somewhat soluble, like quinoline or aniline, or in which it is practically insoluble, as paraffin, only two modifications are obtained, the vitreous and the metallic. The metallic form is stable throughout its range, up to $220^{\circ}$ or nearly; whereas the vitreous form goes over at any temperature above about $60^{\circ}$ to $80^{\circ}$ according to the liquid present. When vitreous selenium is placed in water, it behaves in the same way as it does in other liquids which do not dissolve it. Furthermore, with regard to the behavior of the element at $200^{\circ}$, only one form can permanently exist there. It makes no difference whether fused sèlenium be cooled to $200^{\circ}$, or whether vitreous selenium be rapidly heated to $200^{\circ}$, or again, whether it be allowed to go over at any lower temperature and then raised to that point - the final density at $200^{\circ}$ is always the same and lies along the density curve for metallic selenium. Sunlight causes no change of volume in metallic selenium either at ordinary temperatures or at higher ones, up to $200^{\circ}$. It is not as a rule possible to raise the temperature of vitreous selenium above about $140^{\circ}$ without a sudden change into the metallic form, but it may occasionally, by rapid heating, be brought to $180^{\circ}$ or above before the change takes place. When metallic selenium is kept at ordinary temperatures or placed in a bath heated to $40^{\circ}$, $50^{\circ}$, or $60^{\circ}$, or any higher temperature, below $220^{\circ}$, it shows no tendency to go over into any other form.

The general character of the curves obtained by plotting 
the results of dilatometric determinations with selenitum is illustrated by the accompanying drawing (Fig. 2).

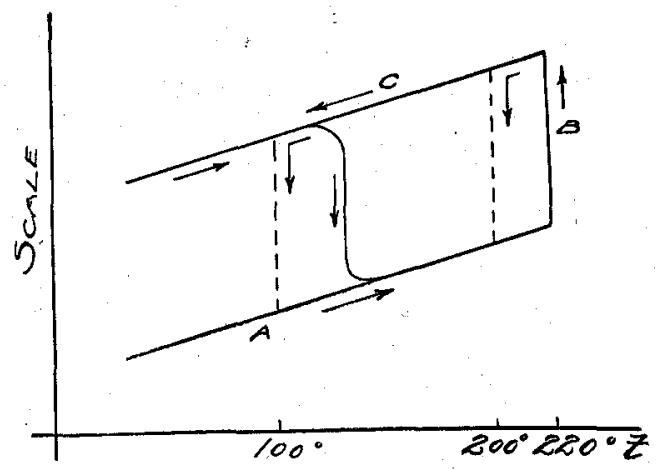

Fig. $2^{1}$

The line A represents the metallic form; the line $\mathrm{B}$, the fusion, with formation of liquid selenium; this when cooled gives the line $\mathrm{C}$; if the cooling be stopped at $200^{\circ}$ we obtain the line $\mathrm{C}_{x}$ leading back to $\mathrm{A}$; if it be stopped at $100^{\circ}$, we get the line $\mathrm{C}_{2}$ also leading back to $\mathrm{A}$. Finally, if the line $\mathrm{C}$ be followed down to ordinary temperatures, it is not usually possible to reproduce it with rising temperature, but the change follows a curve of the general form of $D$, which again leads us back to the line $A$, for the metallic modification.

Two objections may be urged against conclusions drawn from dilatometric measurements regarding the possible transformations of a substance. In the first place, the results only apply to cases where the material studied is in contact with a liquid, in which it will always be more or less soluble; and in the second place, the results, being really only density determinations, will fail to bring out such changes as involve very slight alteration in specific gravity. This latter objection must be let stand, although the probability is always in favor of two different modifications having differences in density which lie within the range of experimental proof. To meet the first objection, a

1 The vertical dotted lines, beginning at the right, should be lettered $C_{1}$ and $\mathrm{C}_{2}$. The intermediate curved line is the line $\mathrm{D}$. 
few density determinations were made, to fill out the gaps left in earlier investigations along this line. They will be found recorded under the corresponding heading.

Vitreous selenium is stable, by itself, at ordinary temperatures, for an indefinite time. Hittorf states that it remains for years without alteration, and the fact that the selenium of commerce is in the vitreous form, further demonstrates its permanence.

To illustrate the degree of its viscosity, a rod of it, having a diameter of about $5 \mathrm{~mm}$. was fastened in a horizontal position and a weight of $200 \mathrm{gr}$. hung upon it at a distance of $6-8 \mathrm{~cm}$. from the point of support. No change could be observed in it at the end of a week. On the other hand, when the substance is fused and drawn into stout threads and these are fastened horizontally, they bend almost at once by their own weight alone.

The vitreous and amorphous forms being both of them liquid selenium, but in different states of division, it follows that their solubilities must also be practically identical. Nevertheless, while the solubility of the amorphous form in carbon disulphide is always admitted, it will be found stated here and there that the vitreous form is nearly or quite insoluble in that liquid.

Thus Schützenberger, ${ }^{x}$ after contrasting the solubility of the amorphous form with the insolubility of the metallic, adds: "Vitreous selenium is also almost insoluble in carbon disulphide." But many points in the description of selenium, in this, as well as in most of the other textbooks, are quite at variance with the truth, often, indeed, in disagreement with facts which have long been known. To show that vitreous selenium does dissolve in carbon disulphide, it is only necessary to place a piece in a little of this liquid for a few moments and follow the immediate change of color.

The data regarding the solubility in this liquid - and they apply equally for the amorphous modification - are as follows: Mitscherlich (I855) states as a rest1t of his experiments that one

${ }^{1}$ Chimie générale, I, 438 . 
hundred parts of carbon disulphide at $46.6^{\circ}$ dissolve o. I part of amorphous selenium, and at $0^{\circ}$, 0.016 part. Rammelsberg (1874) says that one part of selenium (probably amorphons) is soluble in $1376-2464-3746$ parts of carbon disulphide at $20^{\circ}$. We have no details of either of these determinations, but Mitscherlich had noted for the vitreous form as well as the amorphous, that on standing in contact with carbon disulphide, red crystals appear, and he had interpreted this in the case of the vitreous form as not being a change in the mass of the material, but a superficial alteration involving successive solution and recrystallization.

To determine the correctness of this explanation I placed some pieces of vitreous selenium in carbon disulphide, and left them in diffused daylight. On the following day the surfaces were found to have lost their black vitreous lustre, and to have acquired a dull brownish iridescence ; they were, moreover, everywhere covered with minute but well-formed, glittering, transparent red crystals, some of which were loose in the bottom of the vessel, but most of them adhering to the mass of the selenium. After twelve days more, there was no further visible change. The fragments were then removed from the solution, and when broken were found to have their original black fracture within. This shows that Mitscherlich's explanation is correct. The change does not extend within, but stops as soon as the entire surface has become coated with crystals or a crystalline film. It shows also that in all likelihood the crystals are much less soluble than the original material; otherwise this change would be difficult to explain. My experiments have further shown that the change goes on much more rapidly than Mitscherlich supposed.

Now the observation just recorded goes far to clear up the discordant solubility results of Rammelsberg. It is probable that they were obtained by successive determinations from the same material, and that their variation corresponds to the change going on in the solution as it passed from a state of saturation with respect to amorphous selenium, to a state of saturation with 
respect to the red crystals themselves. Hence, while his first value, according, as it does, fairly well with Mitscherlich's, probably represents the solubility of amorphous selenium, the second represents nothing definite at all, and the third is possibly somewhere near the value for the red crystals.

A further experiment of mine showed that vitreous selenium in carbon disulphide in the dark, remained unchanged for six days. At the end of that time, it was allowed to stand in the light for a day and was then found covered with crystals.

Vitreous and amorphous selenium are known to be soluble in various other liquids, but few quantitative measurements have been made.

Retgers (I893), using the powder of commercial vitreous selenium, found its solubility in methylene iodide at $I 2^{\circ}$, to be I. 3 parts in IOO; from this solution, on evaporation, the selenium separates in monoclinic, blood-red leaflets, and also in black opaque aggregations, the latter probably metallic selenium. Schneider (I 866) found that when amorphous selenium is allowed to stand in contact with selenious bromide for eight days, with occasional heating to $70^{\circ}-80^{\circ}$, a solution is obtained which contains in $2 \mathrm{gr}$. of the solvent - probably at ordinary temperatures - $0.44 \mathrm{gr}$. selenium.

Rathke (I 869), in endeavoring to find a liquid which would yield good crystals of the metallic form, noted the solubility of vitreous selenium in carbon di-selenide, selenium di-ethyl, sulphur di-ethyl, and in selenious chloride, which last is capable of taking up very considerable quantities of the element. All forms of selenium dissolve in sulphuric acid, forming a green solution, but no exact study has been made of the degree of solubility. Some further notes on solubility will be found later on, in the description of the other modifications.

Petersen (I89I) found it impossible to get vitreous selenium quite pure. He found that samples prepared by rapid cooling of the fused mass were never free from material which was insoluble in carbon disulphide, though his difficulty may possibly have arisen from impurities in the material. 
Regnault, in studying the rate of cooling of melted selenium to find whether there were any irregularities in the change of temperature, made a series of observations between $260^{\circ}$ and $40^{\circ}$ and found no signs of any irregularity. The apparatus consisted merely of a vessel filled with a large quantity of selenium, with a thermometer standing in the mass. In order to confirm this result, he placed the apparatus in an air-bath at $100^{\circ}$. The readings, which were taken every minute, are as follows :

\begin{tabular}{|c|c|c|c|}
\hline $241.6^{\circ}$ & I $75.95^{\circ}$ & $148 . I^{\circ}$ & I $37.85^{\circ}$ \\
\hline 229.8 & I 70.9 & I 46.3 & 137.0 \\
\hline 219.3 & I 66,4 & 144.7 & 136.25 \\
\hline 210.2 & 162.4 & I 43.25 & I 35.5 \\
\hline 201.7 & I 58.8 & 142.0 & 134.7 \\
\hline I 94.4 & I 55.6 & 140.75 & I 33.9 \\
\hline 187.6 & I 52.9 & I 39.65 & I 33.2 \\
\hline I 81.6 & I 50.4 & I 38.75 & \\
\hline
\end{tabular}

From here on, the readings were made every five minutes:

\begin{tabular}{|c|c|c|c|}
\hline I $33.2^{\circ}$ & I I $5.0^{\circ}$ & I I $4.05^{\circ}$ & II $6.0^{\circ}$ \\
\hline 129.2 & I I 3.4 & I I 5.9 & I 13.35 \\
\hline 125.35 & I I 2.8 & I I 7.9 & I I I 25 \\
\hline I 21.9 & I I 2.6 & I 20.75 & 109.65 \\
\hline II9. I & I I 2.55 & I 21.3 & 108.45 \\
\hline I 16.8 & I I 3.0 & $=\quad$ II 8.9 & $\begin{array}{l}\text { I07.55 } \\
\text { 106.8 }\end{array}$ \\
\hline
\end{tabular}

It will be seen that at about II $3^{\circ}$ there is a marked rise of temperature, followed by a uniform drop like that which preceded. What the cause of this may have been, it is impossible to say; perhaps a partial transformation into metallic selenium, although at that temperature the transformation should have been complete if it had taken place at all; possibly a transformation into one of the red crystalline forms; or possibly merely an experimental variation. At any rate, the observation being of an exceptional character, is worth recording.

\section{Electrification of the vitreous form}

Seebeck (1 826) reports that a rod of selenium (no doubt the vitreous form) becomes negatively electrified when rubbed, though less strongly than sulphur. 
Riess ( 1845 ) confirmed this observation of Seebeck. Berzelius had been unable to observe this phenomenon, though he records in his Lehrbuch that it was noted by Bonsdorff.

My experiments showed that vitreous selenium, when freshly prepared by pouring the melted material on a cold stone slab, shows very marked electrification.

\section{Refraction and dispersion of vitreous selenium}

These properties were investigated by Sirks (I87I) who found the following values:

\begin{tabular}{|c|c|c|c|c|c|}
\hline$n_{\mathrm{A}}$ & $n_{a}$ & $n_{\mathrm{B}}$ & $n_{\mathrm{C}}$ & $n_{c}$ & $n_{\mathrm{D}}$ \\
\hline 2.653 & $2.69 \mathrm{I}$ & $2.73^{\circ}$ & 2.786 & 2.857 & 2.98 \\
\hline
\end{tabular}

Thus the element shows strong dispersive power, as well as very high refraction.

\section{Diathermancy}

Schultz-Sellack (I869) furnishes the following data for the diathermancy of vitreous selenium :

\begin{tabular}{c|c|c}
\hline $\begin{array}{c}\text { Thickness of the } \\
\text { selenium plate }\end{array}$ & $\begin{array}{c}\text {.Percentage of heat passed through } \\
\text { from lamp black } \\
\text { at I00 }\end{array}$ & $\begin{array}{c}\text { from an illuminating } \\
\text { gas flame }\end{array}$ \\
\hline $0.4 \mathrm{~mm}$ & 50 & 36 \\
3.0 & I6 & 5
\end{tabular}

2. Soluble selenium

It is familiar to everyone who has carried out the reduction of selenious acid by sulpluurous acid, in solution, that when the two liquids are mixed, there is often no precipitation at first; the color changes from yellow to a more or less deep red, and only after the lapse of a certain time is a deposit of red selenium formed. This makes its appearance then as a red powder, or as a golden or red translucent skin upon the sides of the vessel.

Schulze (I885) has carried out experiments upon these colored solutions, and his observations, as far as the solubility of the 
element is concerned, have been confirmed by Muthmann ( 1887 ). Schulze's results point to the existence here of a mono- and perhaps a di-selenium tri-thionic acid, $\mathrm{H}_{2} \mathrm{~S}_{2} \mathrm{SeO}_{6}$ and $\mathrm{H}_{2} \mathrm{SSe}_{2} \mathrm{O}_{6}$. These acids are instable in the presence of mineral acids, and it is perhaps by this breaking down that the red solutions are formed which afterwards deposit amorphous selenium.

Schulze has observed that the red selenium precipitated from such solutions redissolves if an excess of water be added, and that it loses this solubility in a short time, especially if exposed to the light. The solution is stable in the dark, but when allowed to stand in the light, deposits selenium in the form of a red film or skin. By dialysis all foreign substances can be removed. The solution may be boiled without decomposition, but the addition of salts and acids throws ont the selenium. Selenium in this form has very strong coloring power; solutions of I part in I0,000 parts of water are distinctly reddish.

If we assume that this freshly precipitated selenium forms solutions in the ordinary sense of the word, and loses its solubility on standing, we are led to the conclusion that we have here to do with a distinct form of the element. If on the other hand we suppose, - what is highly probable, - that the acids described by Schulze are colorless, and that the solutions owe their color to selenium in suspension, then it is quite conceivable that the change in the substance on standing is simply one of aggregation, the extremely small particles deposited from suspension clotting together to larger masses incapable of re-solution. This accords very well with the nature of the red powder and with the familiar observation that at $40^{\circ}-50^{\circ}$ it clots together to a soft sticky mass.

\section{Amorphous selenium}

Even when freshly precipitated seletrium is merely suspended in the liquor, it often remains for hours without settling down. If the vessel be laid aside and the precipitate allowed to come down slowly it forms a soft mass in the bottom of the vessel, resembling in texture and mobility a soft coagulated jelly. When shaken, it does not at first go into powder, but breaks 
along irregular lines. When dried, it forms an impalpable powder which cannot easily be completely removed from any material with which it has come into contact, - the hands, filterpaper, etc.

Hittorf ( $185 \mathrm{I}$ ) records that the red powder of selenium when subject to the heat of the sun's rays becomes partially crystalline, but this was probably a heating effect, or he may have been deceived by the change of color. I have repeated the experiment and find that there is a rapid change in color, but the product appears to be still the amorphous form, though much darkened and clotted together.

When gradually warmed, the powder begins to be somewhat adhesive and clots together, and at about $50^{\circ}$ forms a soft mass, at the same time darkening in color; when this mass is cooled down, it is found to have the brittleness and, if it has been pressed together, the fracture of the vitreous form. This clotting together on warming is a character of the powders of viscous liquids, as is illustrated by the following experiment: Some sealing-wax was reduced to as fine a powder as possible in a mortar, then placed in water and warmed. The powder became first of all adhesive, and at $40^{\circ}-50^{\circ}$ began to clot together. On further raising the temperature, it became quite soft, and after cooling down, it assumed the ordinary brittleness of sealing-wax. The behavior of amorphous selenium is so exactly similar that it would scarcely have been possible to tell which of the two substances was in hand, but for the difference in color. By placing some of the powder in a pastille press, and striking a few sharp blows upon it with a hammer, a hard black mass is obtained, which has a conchoidal fracture, though less brilliant than that of vitreous selenium prepared in the ordinary way. The red powder is never quite free from dust, which interferes with the experiment. These properties all go to show the identity of the amorphous and vitreous forms. If there be any difference at all between them it is a very slight one, and would not justify their being considered as two distinct modifications. For a discussion of the possibility of such a difference, see the section on 
specific gravities. Hittorf (I 848), Regnault (I85I), and others have remarked upon their identity. The amorphous form of selenium is the one which separates by preference in all cases where selenium is rapidly set free, either by decomposing one of its compounds or by precipitation from solution or vapor. This is in accordance with the rule laid down by Ostwald. ${ }^{x}$ The amorphous form is obtained in any of the following ways :

(I) In the ordinary method of purification by dissolving in potassium cyanide and then reprecipitating with hydrochloric acid.

(2) When selenious acid is reduced by sulphur dioxide. Even if both solutions be previously heated, it is still the amorphous form which comes out. In order to test this further, a boiling solution of selenious acid was added to a boiling solution of potassium sulphite; now' at $100^{\circ}$ vitreous or amorphous selenium goes over rapidly into the metallic modification; nevertheless, on mixing the above solutions, the selenium makes its appearance first as a red precipitate, and only after the lapse of a certain time does this become black. In place of sulphur dioxide we may use, in this reaction, iron, zinc, hydrogen, phosphorous acid, stannous chloride, ferrous chloride, chromous chloride, etc. Klages ( 1898 ) records that there is an emission of light when selenious acid is reduced by hydrogen.

(3) From solutions of selenium in concentrated sulphuric acid, on the addition of water.

(4) By the decomposition of selenious bromide by alcohol (Schneider, I866).

(5) By sublimation of the element itself, whereby the amorphous form condenses in the cooler parts of the tube, though it is possible also to obtain crystals of the gray form in this way (Bornträger, I88I).

(6) From various compounds of selenium when decomposed, such as the alkaline selenides (Uelsmann, I 860).

(7) By the electrolysis of solutions of selenious acid, or by passing a current through a selenium cell, whereby amorphous selenium makes its appearance at the anode (Bidwell).

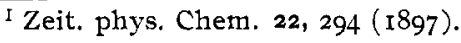


When melted selenium is rapidly cooled, the vitreous form is always obtained. This case is not like the above, being merely an instance of supercooling.

Amorphous and vitreous selenium show an increased reactivity compared with the other forms. This is of importance in the purification of the element by the cyanide method because if selenium be heated in a solution of potassium cyanide, it goes over to the metallic form, and long boiling is then required to bring it into solution, whereas if the amorphous or powdered vitreous material be placed in a cold cyanide solution, the reaction is complete in a very short time. This fact was observed by Schjellerup, ${ }^{I}$ but has been lost sight of in most of the more recent work. Its bearing upon analytical methods and upon commercial processes might prove important.

\section{Behavior of amorphous selenium in solvents}

Mitscherlich (I855) observed that when amorphous selenium is allowed to stand in carbon disulphide for some weeks, it becomes darker in color and more compact, and changes to a mass of red crystals which are, like the original substance, completely soluble in carbon disulphide, though not readily so. The observation was repeated by Schneider (I 866) and later by others. Wishing to repeat the experiment and to find whether the change is influenced by light, I proceeded as follows:

Experiment 44. A small quantity of amorphous selenium was placed in carbon disulphide, the tube sealed and allowed to stand in diffused light. After one day the selenium had become very dark in color, and showed bright crystal faces. On stirring the tube, it was found that this change was only superficial; but upon exposing fresh surfaces, these darkened very rapidly; and in two days the mass had become entirely crystalline in appearance and had assumed a uniform deep cherry red color. The volume of the selenium had also materially diminished. This leads to the conclusion that the change into the crystalline modification goes on much faster than had been supposed, and also

Ann. I09, I25 (1859). 
that it is in some way affected by light. How tar the light effect goes will be better understood from the following experiment:

Experiment 5o. Amorphous selenium in a tube of carbon disulphide, in the dark. After seven days the mass of selenium had become almost entirely crystalline, but showed no change of color. After standing for twelve days longer, the color was a dark cherry red, much deeper than the original color, and the entire mass had become crystalline. This change of color between the two periods may have been due to the exposure of the tube on the first examination, or it may be that the crystals tultimately assume the deeper color even in the dark. Detailed experiments to trace out the connection between these color changes were not undertaken, but it is clear that the absence of light, though it retards the darkening of color, does not prevent the formation of crystals. A later experiment in direct sunlight showed a complete change in one day, the mass becoming uniformly dark in color and completely crystalline.

After these experiments, I turned to the consideration of the behavior of amorphous selenium in contact with other liquids.

Experiment 53. In water. After four days, there was no visible change; after eight days, a perceptible darkening ; after fourteen days, this change of color had become more distinct, but no crystal faces could be observed. During this period of time. the tube had stood at least three afternoons in direct sunlight. After one hundred days, the color was much darkened, but still red.

Experiment 52. In absolute alcohol. After four days the powder had become noticeably darker in color and this change progressed steadily to the end. After eleven days crystal faces made their appearance, and after fifty days the mass was everywhere crystalline and almost completely black.

Experiment 5I. In benzene. After three days there was a visible change of color. After four days glittering crystal faces became noticeable, and after six days the mass had assumed a tniform deep maroon or cherry red color, and was everywhere 
crystalline. During ten days more, there was no change in appearance and the experiment was then stopped. Experiments $5 \mathrm{I}$ and 52 were made under the same conditions as 53 with regard to sunlight.

Experiment 56. In quinoline. The material becomes black at once, in diffused daylight. Under the microscope the progress of the change may easily be watched. It spreads gradually through the mass under ordinary illumination, and is almost instantaneous in direct sunlight. There is no perceptible shrinking together of the selenium, hence the change is probably not the same as that which is brought about in amorphous selenium by raising the temperature. It remains here in a state of extremely fine division and when shaken with the quinoline, does not settle again to the bottom for hours. After the first half hour no further change in color could be observed, although the period of observation extended over forty days. It was impossible to find any signs of crystallinity either with the eye or under the microscope. At the close of the experiment, the selenium was removed from the tube, washed with benzene, and dried. It showed no sign of melting at $215^{\circ}$, but at $225^{\circ}$ melted at once. When shaken in carbon disulphide, it remained for a long time suspended in the liquid - much longer than ordinary amorphous selenium - but, on filtering, the solvent came through clear and colorless.

This shows beyond a doubt that the material goes over in quinoline to the metallic form, and not to the crystalline modification which is obtained, as we have seen, in other liquids. There is here not merely a difference in the rate of change, but a difference in its nature, brought about by the presence of the liquid. It was important then to learn a little more of this change.

A larger quantity of amorphous selenium was placed in quinoline, in diffused light. It remained unchanged for a few moments, then began to darken rapidly, and in fifteen minutes was completely black. After thirty minutes benzene was added and the material filtered and dried. It did not melt at $200^{\circ}$. 
The specific gravity was found to be 4.65 . A second determination after further washing and drying gave 4.59. The variation is somewhat large, but it must be remembered that only a small quantity of material was used. The results show, at least, that the change to the metallic form was not yet complete. A larger quantity - about I gram - of amorphous selenium was then placed in quinoline and left for two days. At the end of that time a specific gravity determination yielded the result 4.86. Hence the change which is at first so rapid, is only superficial. It is probable that each little particle of the amorphous form becomes covered with a coating of the metallic modification which then protects it from further immediate change.

The question arises, whether the action of quinoline is catalytic, or whether it is an effect of solubility, or in some other way proportional to the amount of that liquid present. To answer this, five experiments were made in liquids composed of benzene and quinoline in the following proportions:

(I) Pure benzene

(2) 2 cc " $\quad$ o. I cc quinoline

(3) $2 \mathrm{cc}$

$+0.2 \mathrm{cc}$

(4) $2 \mathrm{cc}$

$+0.5 \mathrm{cc}$

(5) $2 \mathrm{cc}$ $+2.0 \mathrm{cc}$

The selenium in No. 5 blackened within a couple of minutes. That in No. 4 was perceptibly slower in changing, but reached the same end state. In No. 3 it was still not entirely blackened after twenty minutes, and that in No. 2 was, after twenty minutes, only very slightly darker than that in No. I, which had shown no change at all. On the following day, all except No. I were completely black. In (4) and (5) the substance remained, after shaking, a long time in suspension. In the others this was much less marked. It appears from these experiments that the velocity of the change is roughly proportional to the concentration of the quinoline.

An experiment to find whether the reaction goes on in the absence of light showed that it did so, although the results were not accurate enongh to show whether the velocity suffers a diminution in the dark. 
A number of experiments were then tried with amorphous selenium in various liquids, the results of which are given below : Aniline. - After one-half hour, perceptibly darkened; after two days, completely black.

Thiophene.-After one-half hour, no change; after three hours, crystalline without change of color. On the following day, the material showing no further change, $0.5 \mathrm{cc}$ quinoline was added. After fifteen minutes, the selenium had become black, but there were still glittering crystal faces to be seen. After half an hour, these had all disappeared and the mass was uniformly black. This experiment demonstrates the power of quinoline to bring about the same change in the red crystals that it causes in amorphous selenium itself.

Pyridine. - After ten minutes, no change; after one hour, completely black.

Toluene. - After five hours, crystalline and darker in color. No further change after seven days. After thirty days, darker in color.

Benzonitrile. - After one day, crystalline, and darkened. After thirty days more, no further change.

Benzyl cyanide. - After one day, completely black. After fifty days, no further change.

Benzimido-butyl-ester. - After one hour, black; after fifty days, no further change.

Propyl aldehyde. - After two days, no change; after three days somewhat darker, but no crystals. After thirty days, very dark and crystalline.

Piperidine. - Black at once.

Amyl nitrite. - After three days, unchanged. After thitty days, partially crystalline; color unchanged.

Ethyl acetate. - After one day, unchanged; after two days, somewhat darkened; after three days, almost black; without crystal faces; after thirty days, completely crystalline.

Isobutyric acid. - After three days, unchanged; after thirty days, slightly crystalline, no change of color.

Aqueous ammonia.-After one hour, completely black. After fifty days, the same. 
Acetophenone - After one day, much darkened, and crystalline. After three days, almost black, completely crystalline; - after thirty days, no further change.

Nitrotoluene.-After one day, crystalline and darkened. No further change after thirty days.

Brom-nitro-benzene $(m)$ in benzene. - After three hours, crystalline. No further change after thirty days.

p-B-anisaldoxime in alcohol. -After one day, much darkened; after two days, completely black, without crystals. After fifty days, the same.

Hydroxylamine hydrochloride in water. - After three days, unchanged; after thirty days, somewhat darkened in color, not crystalline. Potassium hydroxide was then added, to liberate the base; this brought about no further change in the selenium.

Di-nitro-benzene $(m)$. - After three hours, unchanged. After one day, partially crystalline. After two days, completely so. The change to the crystalline form is always accompanied by a darkening in color, unless otherwise mentioned.

Di-methyl-aniline. - After one-half hour, unchanged; after three hours, crystalline; after thirty days, no further change.

Nitroso-B-naphthol. - After one-half hour, unchanged; after three hours, crystalline; after three days, no further change.

Urea in alcohol. - After two days, very slightly darkened; after thirty days, darkened in color, not crystalline.

Acetone.-After three hours, darkened; after two days, black, no crystals ; after thirty days, black, completely crystalline.

Ammonium sulphocyanate in water. - After thirty days, unchanged.

Picric acid in alcohol. - After thirty days, unchanged.

Tri-ethyl-amine. - Begins to blacken at once; after one day, completely black; after fifty days, the same.

Phenyl hydrazine. - Begins to blacken after a few minutes; after one day, completely black; after fifty days, black, minutely crystalline.

Benzyl-amine. - After one day, darkened; after fifty days, crystalline, almost black. 
Propylene bromide. - After one day, completely crystalline, red; after thirty days, much darker in color.

Di-phenyl-methane. - After one day, unchanged; after fifty days, deep red, crystalline.

Ethyl iodide. - After one day, completely crystalline, red.

Hexamethylene-amine in alcohol. - After one day, nearly black, not crystalline; after fifty days, black.

Acet-anilide in alcohol. - After one day; very slight darkening; after fifty days, considerably darkened; about the same as in alcohol.

Potassium hydroxide in water. - After one day, unchanged. After thirty days, considerably darkened, not crystalline.

Ammonium chloride in water.-After thirty days, unchanged.

Potassium ferrocyanide in water. - After thirty days, unchanged.

Mono-methyl-aniline. - After one day, unchanged; after thirty days, entirely crystalline.

Chloroform. - After one day, unchanged; after thirty days, entirely crystalline.

We see from these results that the substances studied may be divided broadly into three classes. nium.

(I) Those which have little or no action on amorphous sele-

(2) Those which transform it into the crystalline red modification.

(3) Those which transform it into the metallic modification.

In the first class we find water, hydroxylamine hydrochloride, hydroxylamine, urea, ammonium sulphocyanate, picric acid, acet-anilide, potassium hydroxide, ammonium chloride, potassium ferrocyanide.

In the second, alcohol, benzene, thiophene, toluene, benzonitrile, propyl aldehyde, amyl nitrite, ethyl acetate, isobutyric acid, acetophenone, nitrotoluene, brom-nitro-benzene, di-nitro-benzene $(m)$, di-methyl-aniline, nitroso- $\beta$-naphthol, acetone, propylene bromide, ethyl iodide, mono-methyl aniline, chloroform, phenyl hydrazine, benzyl-amine, di-phenyl-methane. 
And in the third, quinoline, aniline, pyridine, benzyl cyanide, benzimido-butyl-ester, piperidine, tri-ethyl-amine, hexamethylene-amine, $p$ - $\beta$-anisaldoxime.

The substances which are most active in bringing about the change to the metallic form will be seen to be ring compounds containing nitrogen in the ring; these without exception all show the same behavior. All the substances which cause this change are nitrogen compounds, but not by any means all nitrogen compounds are capable of causing the change; thus, while aniline acts rapidly in transforming amorphous seleninm into metallic, both mono- and di-methyl-aniline change it into the red crystalline form. It is probable that further study in this field would bring out very interesting results. Meanwhile, it looks as if it could not be a question of solubility alone which explains the difference of behavior of these various liquids.

To determine whether amorphous red selenium would distil over in carbon disulphide to the black form, at ordinary temperatures, an experiment was made in a $\Lambda$-shaped tube filled with carbon disulphide, some of the amorphous substance being placed at one end and some of the black crystals separated from sulphuric acid in the other; but, although the tube remained for several weeks, no change in the size of the black crystals could be observed. The amorphous material changed in a short time to the crystalline variety, but even this, in virtue of its higher solubility, should have displayed the phenomenon; probably the time allowed was too short.

\section{Red crystalline selenium}

The methods by which this form may be obtained have been sufficiently illustrated in the description of the behavior of the amorphous form in solvents. The direct change from the vitreous or amorphous modification to the red crystalline in the absence of solvents, has, as I have stated elsewhere, never been observed with certainty. There is no obvious reason why this change should not go on, and it is quite possible it could actually be observed by bringing the two forms in contact at a moderate heat. 
As an exception to the general rule that selenium separates in the amorphous state when set free, it may be noted here that solutions of selenium in carbon disulphide throw down, on the addition of benzene, a shower of minute glittering plates, of pale red color; the separation is not instantaneous.

The behavior of vitreous selenium in carbon disulphide and Rammelsberg's determinations of the solubility of the amorphous form, point to the conclusion that the red crystalline form has, as we would expect, a lower solubility than those others. Exact measurements in this field are still wanting. The crystals which are obtained from carbon disulphide are very beautiful in form and color, though small. They are readily broken under pressure, and yield a red powder which is indistinguishable from the amorphous modification. The red crystals, which have, in the mass, a dark maroon color, are quite stable at ordinary temperatures. Mitscherlich, who first obtained and studied them, states that they are stable at $100^{\circ}$, but go over at $150^{\circ}$ to the metallic form. Rammelsberg records later that they are instable even at $100^{\circ}$, but Muthmann (I89I), who separated two distinct crystalline forms, places the limit of stability for the first, the ordinary form, at $\mathrm{I} 10^{\circ}-\mathrm{I} 20^{\circ}$, and for the second at $\mathrm{I} 25^{\circ}-\mathrm{I} 30^{\circ}$. The second form is, according to Muthmann, stable at $I 10^{\circ}$.

No further work has been done upon these two forms, the crystallographic properties of which will be considered below.

If their relationship to liquid selenium on the one hand, and to the metallic form on the other, is what I have supposed it to be, then the red crystals should have an instable meltingpoint below 21 $7^{\circ}$. Mitscherlich records an observation bearing upon this, to the effect that these red crystals melt if rapidly heated to $200^{\circ}$.

This observation is perfectly easy to repeat, but it does not prove that the crystals have a melting-point at that temperature. We know, from Regnault's observations, that the heat of reaction in passing from the amorphous to the metallic form is large enough to raise the temperature of the selenium about $200^{\circ}$; but since the red crystalline form is intermediate between these two, it is quite probable that a considerable quantity of heat is 
evolved when it is carried over to the metallic form; hence this apparently real melting-point may represent only what we may call a case of self-fusion, in which a part of the material in going over to the metallic form raises the temperature of the remainder to its melting-point. When some of the powder of the crystals is dropped on a platinum plate, heated by means of an oil-bath to $170^{\circ}$ or above, the powder melts, and this fusion is followed by an immediate transformation to the metallic form. Below $170^{\circ}$ the change goes on more slowly and without fusion. By dropping the powder into a test-tube plunged in the bath, substantially the same results are obtained. Since the crystals are not themselves a form of the liquid modification, it is only necessary to show that, in melting, their temperature does not rise to $217^{\circ}$ in order to establish the instable melting-point. For this purpose, the powder of the crystals was mixed with some high-melting organic compounds, kindly supplied to me by Dr. C. E. Brewer in this laboratory. The compounds used are: anisic acid, melting-point $180^{\circ}$; tri-methyl-acetyl-gallein, I $96^{\circ}$; and gallein acetate, $215^{\circ}$. The corresponding bath temperatures used were $170^{\circ}, 190^{\circ}, 205^{\circ}$, respectively, and in no case was there evidence of fusion of the organic substance. The best results were obtained at $205^{\circ}$, the fusion of the selenium itself being less complete at the other temperatures; at this point the selenium was completely fused, whereas the crystals of the gallein acetate, although in intimate contact with the selenium, remained unchanged.

This experiment, taken in conjunction with the preceding one, shows that the red crystalline form has probably an instable melting-point at $170^{\circ}-180^{\circ}$.

The crystallography of this form of selenium was first studied by Mitscherlich (I855). He noted that selenium separates from carbon disulphide in two different crystal habits: (I) as thin, transparent, red, brilliant leaflets, and (2) as grains which are so intensely colored as to appear opaque and almost black, although thin fragments of them show the transparency and color of the leaflets. He obtained the largest crystals by 
placing amorphous selenium together with carbon disulphide in a sealed tube, and subjecting this to successive changes of temperature between that of the room and a point somewhat below $100^{\circ}$. The crystals so obtained were scarcely $1 \mathrm{~mm}$ broad, but had such well developed faces that it was possible to determine the angles by means of the goniometer.

Mitscherlich finds that the crystals are monoclinic; the better developed ones show a great variety of faces. He made a good many measurements of the angles for which, however, the original article must be consulted.

Muthmanin (I89I) was able to separate two monoclinic forms, both obtained from carbon dist1phide solutions; and he found that they possessed different degrees of stability. With regard to the form studied by Mitscherlich, Muthmann's results are confirmatory in the main. The axial relationships, he found to be

$$
\begin{gathered}
a: b: c=\mathrm{I} .63495: \mathrm{I}: \mathrm{I} .6095 \\
\beta=75^{\circ} 5^{\prime}
\end{gathered}
$$

The commonest faces are $\mathrm{OP}, \infty \mathrm{P} \infty,+\mathrm{P}-\mathrm{P}$, and $\infty \mathrm{P}_{2}$, though Muthmann also finds many other faces upon the better developed crystals. The color is orange red with a not very pronounced semi-metallic lustre.

The second form appears as short thick prisms with very pronounced semi-metallic lustre; they also are monoclinic, but the axial relationships ate different:

$$
\begin{gathered}
a: b: c=\mathrm{I} .59 \mathrm{I} 6: \mathrm{I}: \mathrm{I} \cdot \mathrm{I} 35^{2} \\
\beta=86^{\circ} 56^{\prime}
\end{gathered}
$$

The observed faces were $\infty \mathrm{P}, \mathrm{OP}, \infty \mathrm{P} \infty$, and $\mathrm{P} \infty$. This form comes out sometimes as leaflets which are then easily. confused with crystals of the first form. The color is deep red.

\section{Metallic selenium}

Some of the methods by which this modification can be obtained from the others, have been already indicated. It is in the mass a steel gray metallic substance; when powdered, it gives a black powder, but if the grinding be made finer still, $t$ he sub 
stance is seen to be red. Thus, if a little of the powder be rubbed upon a soft porcelain plate, it becomes so red that it cannot be distinguished from the other forms in the same state of division. There are in the literature many conflicting state. ments regarding the powder and streak of this modification. Thus, Rathke (1869) states that it is black even in the finest powder; and the streak is almost always given as black. Mitscherlich, on the other hand, observed that the streak was red. In my experiments on the changes of the amorphons form in liquids, I observed that the powder which results in quinoline and some of the other componnds used, while it appears black to the eye, always shows a purplish color under the microscope; and it is easy to rub this into a red powder in the way indicated.

In view of the possibility of a reverse transformation from the metallic form back to the vitreous at lower temperatures, I made some experiments upon the red powder obtained from metallic selenium in order to show that it really retained the properties of that form. The first of such experiments was made with some of the powder out of quinoline, and was far from reassuring. I found that when this is rubbed up very fine, so that it is quite red, and then treated with carbon disulphide, it gives a colored solution, indicating the presence of one of the soluble forms of selenium. The powder obtained from some gray metallic selenium which had been prepared by heating the vitreous form for some time to $150^{\circ}$ gave the same result, although in this case the resulting color was less intense, When selenium is dissolved in hot sulphuric acid to purify it, there is often a separation of crystals about the upper surface of the liquid. They are in the form of gray metallic scales and as they separate at a high temperature, it was to be assumed that they would be quite free from the amorphous modification. When finely powdered, they also give a red powder, and this when brought into contact with carbon disulphide colors it, though only very slightly. Plainly, then, the purer the metallic modification is, the less soluble is its powder, in carbon disulphide; and I presume therefore, that if one could prepare 
the metallic modification in quite pure condition, it would no longer show this property at all. With regard to the presence of soluble selenium in the metallic form which was prepared from the vitreous substance, Petersen (I89I) has observed the same thing. He found that the purest metallic selenium he could prepare always contained about one percent of a form soluble in carbon disulphide.

The quantity of material used in the above tests was small, but it has been mentioned in speaking of soluble selenium that one part of that material in I0,000 parts of water, imparted a distinct color to the solution; hence the quantity of the soluble form which would be required to color one or two cc of carbon disulphide, would without doubt, be extremely small.

In making some experiments upon the effect of heat on these red powders, I found it impossible to prepare one which did not turn gray on leating to about $200^{\circ}$ in an air-bath; but on rubbing up again, even at that temperature, the red color always reappears. This observation I am somewhat at a loss to explain. It is due, perhaps, to an alteration in the state of aggregation, but how this is brought about with a substance which melts sharply at $257^{\circ}$ without previous softening, and in a powder which is a mixture of selenium and foreign matter, it would be difficult to say.

In addition to the method of preparation by direct transformation of the other forms, metallic selenium may be obtained by the spontaneous decomposition of solutions of the alkali selenides in contact with the air ; it then forms a crust consisting of very small crystals, which were considered by Berzelius to be tetragonal:

Fabre ( 1887 ) mentions that selenium separates in the metallic form when hydrogen selenide is decomposed by moist oxygen. It is soluble in many organic liquids at high temperatures; in the dilatometer experiments recorded above, beautiful, leaf-like crystals were obtained on heating to $230^{\circ}$ with quinoline, and cooling down. Ethyl benzoate, aniline, naphthalene, and other organic substances also dissolve it at high temperatures. 
Fröbel (I 840 ) made a microscopic study of the crystals which separate from a solution of ammonium selenide and pronounced them to be orthorhombic.

The crystal form of metallic selenium has been studied by Muthmann (I 890 ) who prepared the crystals by sublimation. Earlier observers had in most cases studied those crystals which separate from solptions of selenides of the alkalies, and in this way none were obtained of sufficient size to make measurements possible. Muthmann finds them hexagonal, thombohedral and fully isomorphous with tellurium. The observed faces were $\infty \mathrm{R}$ and $\mathrm{R}$.

\section{Heat conductivity}

Bellati and Lussana (I 887) observed that the heat conductivity of selenium was increased by illumination. They covered a circular plate of crystaline selenium with the double salt $\mathrm{HgI}_{2} \mathrm{CuI}_{2}$, and heated it at a point by means of a hot platinum wire. The double iodide is red at ordinary temperatures, brown above $70^{\circ}$, and hence the area of change of color is a measure of the heat conductivity. They guarded against heating effects from the source of light and found that direct sunlight increased the heat conductivity $8-25$ pct. Even the light of a gas flame had a perceptible effect.

\section{Heat of transformation of liquid selenium into the metallic modification}

The first determination of this heat value was made by Regnault (I 856). The figures obtained by him have scarcely more than a qualitative value, but are quoted here for the sake of comparison with the later results of Petersen (I89I).

Regnault's method was to place a mass of about 200 grams of vitreous selenium in an oven at $100^{\circ}$. A thermoneter standing in the selenium was then read every minute. When the temperature reached about $98^{\circ}$ the substance began to go over to the metallic form and the temperature rose to about $2 \mathrm{I} 4^{\circ}$, subsequently dropping to $100^{\circ}$. The main corrections are (I) for the heat absorbed in the containing vessel and (2) for the loss by radiation; the first of these is made on the basis of a pre- 
vious determination of the water-equivalent of the vessel, the second by noting the normal rate of change per minute in the temperature of the selenium when no transformation was going on in the mass. Regnault reached the conclusion that the reaction set free enough heat to raise the temperature of the selenium from $98^{\circ}$ to about $329^{\circ}$, i. e. through 23 I degrees. A second determination was made by another method which is even less exact, and the results so obtained indicated that the heat of reaction would raise the mass of selenium from $0^{\circ}$ to $180^{\circ}$.

Regnault concludes that vitreous selenium in passing over to the metallic form sets free enough heat to raise its own temperature about two hundred degrees. In other words, taking the specific heat of vitreous selenium as O.I, we have the value about I $5 \mathrm{~K}$ for one gram-equivalent of selenium.

Before passing on to consider the determinations of Petersen we must mention the researches of J. Thomsen ${ }^{\mathrm{I}}$ which bear indirectly upon this point and are of especial interest in connection with a possible difference between the vitreous and amorphous forms of selenium. Thomsen determined firstly the heat involved in the reaction :

$\mathrm{SeO}_{2} \mathrm{Aq}+2 \mathrm{HClAq}+2 \mathrm{NaSHAq}=2 \mathrm{NaClAq}+2 \mathrm{H}_{2} \mathrm{O}+\mathrm{Se}+\mathrm{S}_{2}$.

The solutions used had the molecular composition:

$$
\begin{aligned}
& \mathrm{A} \ldots \mathrm{NaSH}+6 \mathrm{I} 6.7 \mathrm{H}_{2} \mathrm{O} \\
& \mathrm{B} \ldots \mathrm{SeO}_{3}+2 \mathrm{HCl}+{ }_{1500 \mathrm{H}_{2} \mathrm{O} .}
\end{aligned}
$$

In each experiment $I / 3 \circ$ of the corresponding weight of $A$ and $I / 60$ of that of $B$ was used.

The total heat value is made up as follows :

$$
\mathrm{R}=\left\{\begin{array}{l}
2(\mathrm{NaOHAq}, \mathrm{HClAq})-2\left(\mathrm{NaOHAq}, \mathrm{SH}_{2}\right) \\
+2\left(\mathrm{H}_{2}, \mathrm{O}\right)-2\left(\mathrm{H}_{2}, \mathrm{~S}\right)-\left(\mathrm{Se}, \mathrm{O}_{2}, \mathrm{Aq}\right)
\end{array}\right.
$$

$\mathrm{R}$ is found experimentally to be $733.98 \mathrm{~K}$; introducing this along with previously known values, we get

$$
733.98=274.80-249.80+1367.14-94.80-\left(\mathrm{Se}, \mathrm{O}_{2}, \mathrm{Aq}\right),
$$
whence $\left(\mathrm{Se}, \mathrm{O}_{2}, \mathrm{Aq}\right)=5^{6} 3.36$. It will be seen from the nature

${ }^{1}$ Thermochem. Unters. 2, 269, 3 I 3. 
of this reaction that the heat value here found refers to amorphous selenium.

Thomsen determined, secondly, the heat of formation of the chloride $\mathrm{Se}_{2} \mathrm{Cl}_{2}$ from "ordinary amorphous selenium, prepared by cooling the melted substance", i. e. from the vitreous form.

Three separate determinations gave $221.29-219.85-$ 223.35 , the mean being $22 \mathrm{I} .5$. From the chloride $\mathrm{Se}_{2} \mathrm{Cl}_{2}$ he determined the heat of formation of the chloride $\mathrm{SeCl}_{4}$, and finally by finding the heat of reaction of this substance with water, obtained as an independent result for the reaction $\left(\mathrm{Se}, \mathrm{O}_{2}, \mathrm{Aq}\right.$ ), 559.86. Thomsen considers these two results in satisfactory agreement, although he suggests that a slight difference in the physical state of the selenium in the two cases may explain the variation. It is of interest to note that the difference is in the direction of greater heat of reaction for selenium in the amorphous state. This falls into line with what is said below. in the chapter on specific gravities, regarding a possible difference between the two forms.

Fabre (I887) measured the heat of transformation of liquid selenium into crystalline, by placing the material in the calorimeter and warming it by adding sulphuric acid to water in a larger tube, which surrounded the one containing the selenium; after the reaction was over, these tubes were broken and a correction then introduced for the heat of dilution of the sulphuric acid in the total water-content of the calorimeter.

By this ingenious device, he was able to measure directly the heat of reaction. His results are as follows:

For one gram-equivalent of vitreous selenium

$$
52.2 \quad 57.2 \quad 58.2 \quad \text { mean } 55.8 \mathrm{~K} \text {. }
$$

For red precipitated selenium

$$
5 \mathrm{I} .2
$$

mean $53 \cdot 4$.

These results are practically identical, within the limit of experimental error. They indicate that Regnault's value is far too low, a conclusion that is only confirmed by later results. The 
material used by Habre was afterwards tested as to its specific gravity, and found to give as a result, 4.78 for the first, and 4.79 for the second; hence the transformation was probably complete.

Fabre used an indirect method to confirm these conclusions, namely the action of bromine in bromine water, upon selenium. For the metallic modification he found the values $431.6-432.4$ - 42I.O; mean 429. Unfortunately, we are not told how the material was prepared.

The crystals which separate from solutions of selenides of the alkalies gave $432-434$; mean 433. Vitreous selenium prepared by rapid cooling, on a porcelain plate, from the fused state, gave $480-495.6-485.2$; mean 486.8. The difference in the two cases may be taken at about $57 \mathrm{~K}$, a result which agrees fairly well with that obtained by direct measurement.

Finally Petersen ( 1891 ) redetermined by indirect methods the heat of transformation from the amorphous to the metallic and to the red crystalline form.

For the heat of formation of the chloride $\mathrm{Se}_{2} \mathrm{Cl}_{2}$ from vitreous selenium prepared by pouring the melted element into water, he obtained values which vary in four experiments from $240^{\circ}$ to $250^{\circ} \mathrm{K}$. Thomsen's value obtained from essentially the same material was $22 \mathrm{I} .5$. Petersen finds in this difference ground for the assumption that there are two different soluble vitreous forms of selenium. It is much more likely that these variations are experimental, especially since Petersen has himself shown that vitreous selenium always contains more or less of the metallic modification.

From the monoclinic red crystals which separate out of carbon disulphide, Petersen finds the heat of formation of the chloride $\mathrm{Se}_{2} \mathrm{Cl}_{2}$ to be $207.5 \mathrm{~K}$. From Thomsen's data, using this value, we obtain for the heat of formation of the oxide $\mathrm{SeO}_{2}$ from the monoclinic form, $562.0 \mathrm{~K}$. Deducting this from 572.5 , Thomsen's result for the oxidation of amorphous selenium, we get $10.5 \mathrm{~K}$ as the heat of transformation of that form into the red crystalline. By a direct comparison of the results for the heat of formation of the chloride from monoclinic and vitreous selenium 
we find quite a different value; but they both point at least in the same direction, that the heat value in the change from liquid selenium to monoclinic red, is positive.

Metallic selenium was prepared by Petersen by heating the element to $25^{\circ}$, then cooling to $180^{\circ}$, maintaining this temperature for a long time, and then slowly cooling. So prepared, it contains about one percent of soluble selenium. The value for the heat of formation of the chloride $\mathrm{Se}_{2} \mathrm{Cl}_{2}$ from this form is $200.0 \mathrm{~K}$, and for the crystals from selenide solutions $199.8 \mathrm{~K}$. This gives, by calculation, for the heat of formation of the oxide $\mathrm{SeO}_{2}$ from metallic selenium, $55^{8.2} \mathrm{~K}$, a value which differs by I 4.3 from Thomsen's result for the amorphous form. It should be mentioned that Petersen, in quoting Thomsen's data, makes a correction of $9 \mathrm{~K}$ in them for the heat of solution of $\mathrm{SeO}_{2}$, as Thomsen's results refer to reaction in solution. Summing up the results thus far obtained, we have for the heat of transformation of liquid into metallic selenium:

$\begin{array}{ll}\text { Regnault (direct) } & \text { I5 K } \\ \text { Fabre (direct) } & 55 \\ \quad \text { (indirect) } & 57 \\ \text { Petersen (indirect) } & \text { I4.3 }\end{array}$

For the change from the amorphous to the vitreous form we have the very doubtful value deducible from Thomsen's restilts, 3.5 ; and for the transformation from that form to the red monoclinic, 10.5 .

\section{The specific heat of selenium}

Determinations of the specific heat of liquid selenium at any temperatures above $60^{\circ}$ necessarily give uncertain values because of the danger of some of the element going over to the crystalline form. The heat set free in this transformation has so large a value that the change of even a very small quantity would utterly falsify the results. The determinations of the specific heat of the crystalline form are not open to this objection, provided the transformation into this form has been effected completely. 
The data regarding the specific heat of the different modifications of selenium are to be found in the papers of Regnault (I840 and I856), Neumann (I 865), and Bettendorf and Wüllner (i 868). Regnault's first determination was undertaken with some material which showed no appreciable sulphur content, but which was not tested for tellurium; nor are any particulars given as to how the material was treated before the determinations were made. The values, when compared with later results, show that he had in hand here, in all probability, the gray metallic modification. The two forms were not well differentiated at that time. Regnault made three determinations, and found for a range of temperature from $98^{\circ}$ to $12^{\circ}$, the values:

$$
0.08349, \quad 0.08396, \quad 0.08368 ; \quad \text { mean } 0.0837 \mathrm{I} \text {. }
$$

Sixteen years later he returned to the subject. This time he made himself familiar with the change from the vitreous to the metallic form. An analysis of the material gave Se 97.75 pct, Te 2.25 pct. Here again we have no information concerning the preparation of the material, but are told merely that it was metallic selenium. The results for a range from $98^{\circ}$ to $20^{\circ}$ are $0.075 \mathrm{I} 7,0.07563,0.07675,0.07709$; mean $0.076 \mathrm{r} 6$. The method used by Regnault in both of these investigations was the ordinary calorimetric one, by heating the substance to a higher temperature, dropping it into a large mass of water, noting the rise in temperature, and correcting for the alteration in this rise due to radiation and to the cooling effect of the surrounding atmosphere.

A determination with vitreous selenium between $87^{\circ}$ and I $9^{\circ}$ gave the results :

$$
\text { 0.1036, 0.1026; mean 0.103I. }
$$

At lower temperatures the values were as follows:

$$
\begin{array}{r}
\begin{array}{rr}
\text { Vitreous form }-27 \text { to }+8^{\circ} & 0.0746 \mathrm{r} \\
-20 \text { to }+7^{\circ} & 0.07476 \\
\text { mean } & 0.07468
\end{array} \\
\begin{array}{rr}
\text { Metallic form }-20 \text { to }+7^{\circ} & 0.07323 \\
-16 \text { to }+7^{\circ} & 0.07570 \\
\text { mean } & 0.07446
\end{array}
\end{array}
$$


Thus at low temperatures the specific heat appears the same whichever form we have in hand. These results show a large variation from the earlier ones of the same author; it is unfortunate that no information is given regarding the preparation of the material; there are not even sufficient data to make possible a recalculation of the results.

In the light of his earlier values, and of the later work which we shall have to consider below, there can be little doubt that the specific heat of metallic selenium is about 0.084 , a value which varies widely from the above. It is difficult to imagine that Regnault by any error used vitreous in place of metallic selenium in the later determination; on the other hand, it is possible that he was here dealing with the red.crystalline form; true, the direct production of this modification from the vitreous has never been observed with certainty, but it is not in the nature of the case impossible; and there are other isolated instances on record where the assumption of such a change is at least a convenience.

The next specific heat determinations are those made by Neumann, in Göttingen, in I865. The method used was Regnault's. His experiments were confined to the metallic form which, it is to be inferred, was prepared by heating vitreous selenium in the water-bath. As a mean of thirteen determinations, varying from 0.0847 to 0.0872 , he finds the value 0.0860 . Neumann used an arbitrary thermometer, but the range over which he worked was from the temperature of boiling water down to about $2 \mathrm{I}^{\circ}$.

Finally, in I868, Bettendorf and Wüllner published the results of their determinations. They followed essentially the same method as Regnault, simplified in certain details according to the procedure of Kopp. Their statement that Regnault prepared his material by heating the red powder obtained from selenious acid solutions finds no support in Regnault's original papers. Furthermore, their conjecture that Neumann worked with a mixture of two forms is unnecessary. It is based on the abnormally low value for the specific gravity of Neumann's 
material, but this is shown elsewhere to have been most probably due to experimental error.

Metallic selenium. Bettendorf and Wiillner prepared their material by heating amorphous selenium in an air-bath at $100^{\circ}$ for a week. The substance was then gray in color, and had the specific gravity 4.797 . Their values are:

$$
\begin{gathered}
0.0840, \quad 0.0839, \quad 0.0846,0.084 \mathrm{I}, \quad 0.0828,0.0850, \\
0.0870 \quad 0.0829, \quad 0.0825 ; \text { mean } 0.0840 ;
\end{gathered}
$$

the range of temperature being from $60^{\circ}$ down to $25^{\circ}$.

A second specimen prepared in an entirely different way gave the same result: The material in this case was the crystals which separate from solutions of selenides of the alkalies on standing in contact with the air. The following values were obtained: $0.0842,0.0838,0.0836,0.0847,0.0835$; or in the mean 0.08399 , the range of temperature being the same as before.

Vitreous selenium. The material was prepared by dropping melted selenium into cold water; since vitreous selenium softens at $40^{\circ}$ to $50^{\circ}$ the determinations were restricted to temperatures below $38^{\circ}$. The results are as follows : $0.095^{2}, 0.095^{8}, 0.095^{\circ}$; mean 0.0953 , the range of temperature being from $3^{\circ}$ to $20^{\circ}$. For higher temperatures, the following results were obtained:

\begin{tabular}{c|c} 
Temp. & Spec. heat \\
$53-22^{\circ}$ \\
$62-20^{\circ}$
\end{tabular}

There is a possibility that these large values may be due to a certain amount of the selenium having gone over to the metallic form. They could be checked by making a determination in the reverse way, i. e. by introducing the cold substance into a hot bath; here, if any such change went on, the values would come out too low.

The above results are, in summary, as follows: 
Vitreous selenium

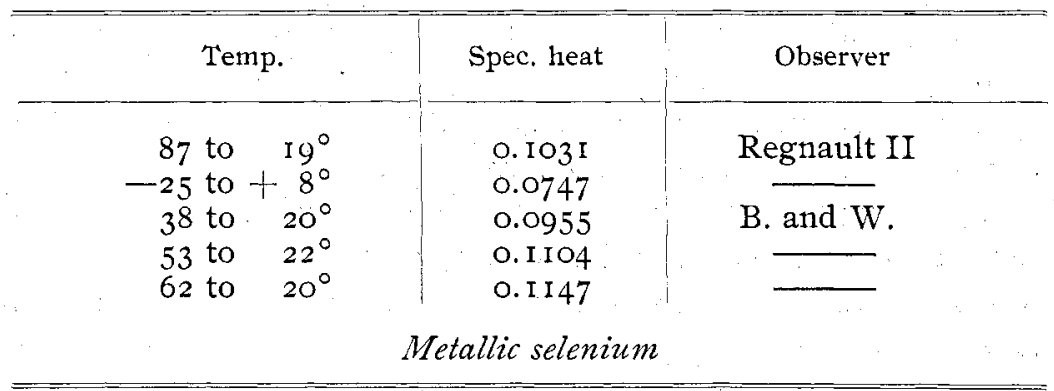

\begin{tabular}{r|l|l}
98 to $12^{\circ}$ & 0.0837 & Regnault I \\
98 to $20^{\circ}$ & 0.0762 & Regnault II \\
20 to $-7^{\circ}$ & 0.0745 & \\
100 to $20^{\circ}$ & 0.0860 & Neumann \\
60 to $25^{\circ}$ & 0.0840 & B. and W.
\end{tabular}

Person $^{\mathrm{x}}$ determined the specific heat of ordinary bees' wax, a substance which, like vitreous selenium, gradually softens on being warmed. His results are:

\begin{tabular}{r|l} 
Temp. & Spec. heat \\
\hline$-21^{\circ}$ to $3^{\circ}$ & 0.4287 \\
$6^{\circ}$ to $26^{\circ}$ & 0.504 \\
$26^{\circ}$ to $42^{\circ}$ & 0.82 \\
$42^{\circ}$ to $58^{\circ}$ & 1.72
\end{tabular}

\section{Specific gravity determinations}

The difficulty in determining the specific gravity of selenium lies in the fact that even the smallest particles of it may contain air cavities ; so that it is usually necessary, in order to get satisfactory results, that the material shall be in a state of fine powder and that it shall be subjected to exhaustion. The easiest way to effect this is to cover the powder with some of the liquid used for filling the specific gravity bulb, place this in a desiccator, and pump out. The liquid used may be alcohol or benzene. It is to be noted that when alcohol is used, it is best, if the liquid be not pure, to pour off that part of it which has stood over the

× Ann. [3] 27, 263 (1849). 
selenium when exhausted, since it may have suffered a change of density due to the vaporization of the more volatile component.

The determinations recorded below were all made at $25^{\circ}$ in a specific gravity bottle of capacity $5^{\circ} \mathrm{cc}$. This was left in a bath at constant temperature for fifteen minutes. In order to test whether this was a sufficient time, the bottle was. replaced in one instance, after weighing, and left in the bath for two hours longer; at the end of that time the difference in weight was only I ming. The bath used was an ordinary Ostwald thermostat provided with a thermo-regulator of the ustral size, but filled with toluene. This forms an instrument of a very high degree of sensitiveness, so that it was possible to keep the total variations in temperature within $0.01^{\circ}$ for hours at a time.

It was found better to dispense with the usual stopcock where toluene was used; this was done by altering the gas-entry tube as indicated in the accompanying figure. (Fig. 3.) The

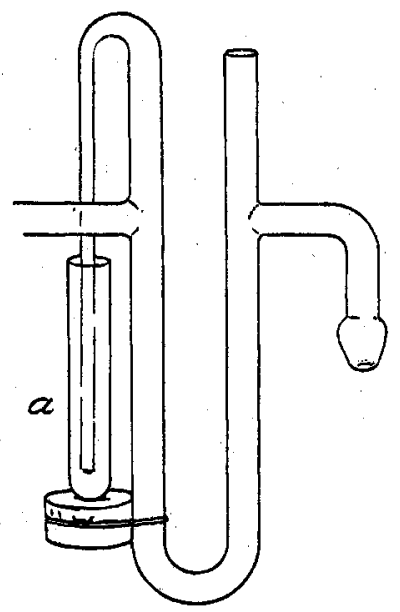

Fig. 3

tube $a$ is partly filled with mercury, and when the desired temperature has been reached, is slipped over the end of the drawnout tube, and held in place by a cork tied on to the neighboring upright. The rest of the piece is arranged in the usual manner. 
An attempt to use the floating method with amorphous selenium failed. The double nitrate of thallium and silver ' gives a liquid of sufficient density, but selenium is at once acted upon by it.

The specific gravities of the different forms of selenium have been very : often determined, and sometimes with widely varying results. The variations have been, in the main, due to the difficulty mentioned above. When the element is present in fragments, these contain air cavities which render specific gravity determinations quite hopeless. ${ }^{2}$ The only method by which uniform results can certainly be obtained is to powder the material and then exhaust for some time, best under the liquid in which the density is to be determined. This liquid should not be water, because it does not readily wet any one of the modifications of selenium; alcohol has been used in all of the more careful determinations.

Berzelius (I8I8), who had observed the change from the vitreous to the gray form, records the specific gravity of the former at

$$
4 \cdot 3-4 \cdot 32
$$

and says that the transformation into the gray form causes no change of density.

The next data are those of Schaffgotsch (I848), who recognized the difficulties to be encountered and avoided them by making the weighings in alcohol and exhausting to get rid of the adhering air. He found at $20^{\circ}$ for vitreous selenium, 4.276 to 4.286 ; for metallic selenium, prepared by heating to $250^{\circ}$ on a sand-bath, and very slowly cooling, 4.796 to 4.805 ; and for the amorphous red form, 4.259 to 4.269 .

Hittorf (185I) determined the density of the crystals which separate from solutions of selenides of the alkalies, and found the value 4.808 ; he gives no information regarding his method of determination.

' Retgers. Jahrb. f. Min. I893 and 1896 .

2 The same kind of difficulty is encountered in determining the specific gravity of tellurium. See Lenher and Morgan. Jour. Am. Chem. Soc, 22, 29 (1900). 
In I853, Schaffgotsch returned to the subject and made a series of more elaborate determinations.

I. Vitreous selenium, prepared by rapid cooling, from the fused element:

Four determinations with fragments which proved afterwards to contain air cavities, and with powder which, although boiled with water, was not rendered free from air, gave values varying by but little from 3.9. The powder, on being boiled, must certainly have gone over to the metallic form, yet Schaffgotsch. records the density observed in this case as 3.9267 ; which goes to show how large the errors due to air cavities may be, and, particularly, the importance of choosing an appropriate liquid in which to work.

A second series, carried out with fragments which were not investigated with regard to enclosed air, gave 4.259 to 4.269 .

The third series was made with air-free vitreous selenium (Schaffgotsch appears to have satisfied himself of this by inspection only), and with powder which was freed from air by repeated exhaustion under water or determined in alcohol, which, the author says, renders the use of the air-pump unnecessary. The results are very concordant, varying only from 4.276 to 4.286 ; or, in the mean, $4.28 \mathrm{r}$.

II. Metallic selenium, prepared by melting and then very slowly cooling, gave, when powdered and determined under alcohol, values which varied in four determinations, between 4.796 and 4.805 .

III. Amorphous selenium - selenium blood as Schaffgotsch calls it - gave varying results, from 4.245 to 4.275 . After causing it to coagulate by heating to $50^{\circ}$, the results ran from 4.250 to 4.277 , thus showing no difference from the powder. These last determinations were made in water. Schaffgotsch considers that, in view of the difficulties of the determination, the results are to be considered as indicating a density identical with that of vitreous selenium. The material was prepared by the addition of hydrochloric acid to a solution of selenium in sodium sulphite. 
Mitscherlich (1855) studied the two red forms which separate from carbon disulphide solutions and found their specific gravity to be 4.46 to $4.5 \mathrm{I}$. He seems to have taken the two forms as being identical except in crystal habit, and his density determination was possibly made with a mixture of the two. He states that it was possible by heating them to $5^{\circ}{ }^{\circ}$ to transform them into the gray modification, whose specific gravity he found to be 4.7 . The determinations were made in alcohol at $15^{\circ}$ and without powdering the material. The crystals which separate from selenide solutions had a density, according to Mitscherlich's results, of 4.76 to 4.79 . Both of these forms - the black crystals as well as the gray material obtained from the red crystals at $150^{\circ}$ - he therefore considered to be identical with the ordinary gray selenium whose density Schaffgotsch had found to be 4.80 .

Neumann (I865) made a determination of the specific gravity of metallic selenium, and records the density of this substance "in fragments" as 4.4I. This value, lying as it does so far below 4.8 , suggested the possibility of there being a second form of gray metallic selenium, and most of the modern textbooks describe two forms. The only further confirmation of this view is supplied by the experiments of Rammelsberg (I 874) which will be found discussed below.

The next density determinations were those of Bettendorf and Wüllner (I868), who were also engaged upon the question of specific heat. The only value they give is for a sample of red amorphous selenium, which had been heated for a week in a steam-oven, and had at the end of that time a density of 4.797 at $20^{\circ}$. No details of the work are given, but it is obvious that they had in hand the gray form. The accuracy of the value found is due to the fact that the material, being obtained from the red powder, was already in a state of fine division, and hence no considerable error from air cavities should enter in. We come then to the paper by Rammelsberg (I874). The discrepancy between the results of Neumann's observations and those of earlier investigators seemed, to Rammelsberg, to call for a redetermination of the specific gravity of all the various forms of 
selenium. His determinations were made partly in alcohol, partly in water; but it does not appear that the material was powdered, nor that the air-pump was used, except perhaps in the determinations under water.

The amorphous variety obtained by the reduction of selenious acid in solution, by sulphur dioxide, gave values between 4.27 and 4.34 , while melted selenium, i. e. vitreous, gave 4.29 to 4.36. The crystals obtained from carbon disulphide, which are described as brownish red and transparent, were subjected to a large number of separate determinations in alcohol; only small quantities of the crystals were used, and with very variable results, the mean values of which are given as

$$
4.418-4.54-4.59 \text {, }
$$

i. e., about the same as Mitscherlich had found. For the crystals which separate from selenide solutions the figures given are

$$
4.77-4.79-4.86 \text {. }
$$

But the most interesting values are those which Rammelsberg found for the gray metallic selenium which he prepared by heating the vitreous form to $I 20^{\circ}-I 50^{\circ}$. The product is described as insoluble in carbon disulphide and it may therefore be assumed that it contained no considerable quantity of the vitreous form unchanged. The results for determinations made partly in alcohol and partly in water, are

$$
4.437-4.464-4.487-4.545-4.563-4.590 \text {, }
$$

or, in the mean, $4.5^{\mathrm{I}} 4$. One would have thought that the extremely large variation in these results would have aroused Rammelsberg's suspicions as to their value; but apparently not. He remarks merely that they all lie very much nearer to Neumann's value, 4.4 , than to Schaffgotsch's of 4.8 , which is not the case. Neumann expressly states that his figure referred to selenium "in fragments," and Rammelsberg leaves the same to be inferred regarding his, whereas Schaffgotsch's determinations were made with powdered material.' I made an experiment to find what difference would be observed in the density of the same material in fragments and in powder. To this end, about two 
grams of vitreous selenium were heated for an hour at $120^{\circ}-150^{\circ}$. The product was entirely gray, and the fracture had the same color; no trace of the red form could be observed in it. The determinations were made in alcohol at $25^{\circ}$. The first was made with the material broken up only enough to allow of its being brought into the specific gravity bottle. The value found was 4.55. The selenium was then taken out, dried and powdered, replaced in the bottle, covered with alcohol, pumped out for half an hour, and then re-determined. The new value was 4.77. In view of these results there can be little doubt that both Rammelsberg and Neumann had in hand ordinary metallic selenium, and that the variations from the true value 4.8 displayed by their results, are due to experimental error. This view is confirmed by the fact that Neumann found the same value for the specific heat as did Bettendorf and Wuillner, while these authors found 4.797 for the density of their material. As a further illustration of the extent to which error of this kind is possible, attention may again be called to the remark of Berzelius that the change from the vitreous to the metallic form causes no change whatever in the density (4.3). The accuracy of Rammelsberg's results with the other modifications is due to the fact that these forms having separated from solution, do not contain air cavities.

A number of density determinations were made by Petersen (I89I), who prepared metallic selenium by heating the vitreous modification to $250^{\circ}$, then cooling to $\mathrm{I} 80^{\circ}$ and keeping it at that temperature for a long time; finally the material was slowly cooled. It was found to contain about one percent of soluble selenium. The density determined at $I 7^{\circ}-I 8^{\circ}$ was found to be $4.63(4.62-4.64)$. The explanation for this very low value is to be found in the fact that the determinations, though carefully made, were carried out in water, which has always yielded unsatisfactory results with this form of the element. We have seen that Schaffigotsch obtained in this way a value as low as 4.39 . The method of procedure used by Petersen was to bring the substance into the pycnometer, cover with air-free water, 
warm, place under the pump, and pump out until the water was caused to boil. That author drew from his result the conclusion that specific gravity cannot be taken as a criterion for the crystalline forms of selenium. But this conclusion hardly seems called for, considering that all determinations carried out with alcohol under appropriate conditions have yielded, for the metallic form, values which lie very near to 4.8 .

The monoclinic red crystals obtained by extraction of amorphous selenium with carbon disulphide, yielded, by the same method as above, the values 4.44-4.47. When compared with Mitscherlich's results, which are, as before pointed out, not free from possible error, this gives as the most probable value for the density of monoclinic red selenium, a figure not differing by much from 4.47 .

It will be noticed that all accurate determinations of the densities of amorphous and vitreous selenium yield results indicating a slightly lower value for the amorphous form. The following are the data on the subject:

\begin{tabular}{|c|c|c|}
\hline & Amorphous & Vitreous \\
\hline Schaffgotsch (1848) & $4.259-4.264$ & $4.276-4.286$ \\
\hline Rammelsberg & $4.27-4.34$ & $4.29-4.3^{6}$ \\
\hline
\end{tabular}

The difference is so slight as to be quite within the limits of experimental error, and the observers themselves have generally attributed it to that source; yet its constant recurrence, always in the same direction, leads to the conclusion that the two forms may really possess slightly different densities, although representing one and the same modification of the element. If this is so, the difference is due to the fact that the material exposes in one case a maximum, in the other a minimum of surface; for the amorphous form, which gives colloidal solutions with water when freshly precipitated, is in a state of extremely fine division. It is quite possible that the difference in the state of aggregation should cause a difference in density as well as in 
other properties of the substance. Any experiments made with selenium itself with the idea of establishing such a difference would be rendered inconclusive by the possibility of the formation of a small amount of metallic selenium during the course of the experiment. It is, on the other hand, very easy to find analogous cases among the other elements; colloidal solutions have been prepared of gold, silver, copper, mercury, sulphur, and other elements, and all of these are obtainable in the form of impalpable powders, quite different in appearance from the compact material. Some experiments are now in progress to determine whether a measurable difference of density exists in such cases. This is not improbable if the idea suggested by van der Waals ${ }^{\mathrm{I}}$ be correct - that there is no discontinuous change between a liquid and the vapor above it; for if there is a film of intermediate density in the case of an ordinary liquid, and its vapor, it is entirely probable that solids would also have a bounding surface of lower density than the material within; equally so a viscous substance like amorphous selenium. Increasing the surface for a given weight of material would then always bring about a lowering of the density, and if the surface were made relatively very large, this lowering might become apparent.

Summary of specific gravity results

The most careful determinations which have been made of the specific gravity of the various forms of selenium lead to the following results for the different modifications, at ordinary temperatures :

\begin{tabular}{l|l}
\hline Amorphous & 4.26 \\
Vitreous & 4.28 \\
Red crystalline & 4.47 \\
Metallic & 4.80
\end{tabular}

\section{Atomic volumes}

Taking the atomic weight as 79.2 , these values give the following atomic volumes:

\begin{tabular}{l|l}
\hline Amorphous & 18.6 \\
Vitreous & 18.5 \\
Red crystalline & 17.7 \\
Metallic & 16.5
\end{tabular}

${ }^{x}$ Ostwald Lehrb. I, 540. 


\section{I0. Conductivity of selenium. Action of light}

Beyond a vague experiment of $K_{n}$ ox (1839) there is no information of value regarding the conductivity of selenium before $185 \mathrm{I}$, when Hittorf found that the vitreous form was a very good insulator, whereas in the metallic state the element conducts electricity fairly well, and furthermore shows an unusual property, in that, unlike typically metallic substances, but like tellurium, its resistance decreases with rising temperature up to the point of fusion; at that point it suddenly increases. Hittorf used carbon plates as electrodes in his experiments.

In 1873 Willoughby Smith announced that the resistance of selenium to the passage of electricity was diminished by light. We have no details regarding the preparation of the selenium, which was in rods 5-IO $\mathrm{cm}$ long, and $\mathrm{I}-\mathrm{I} .5 \mathrm{~mm}$ thick. They were, plainly, of the metallic modification, as the later correspondence shows, and were sealed in glass tubes, through the ends of which platinum wires were fused for the purposes of connection. Even the light of an ordinary gas burner was found to exercise a marked influence upon the conductivity, which rose and fell according as the cell was exposed to the rays of the burner, or shaded by interposing the hand. The difference with even so feeble a source of light as this amounted to 15 to 20 percent. "If the light be intercepted by rock salt or by glass of various colors, the resistance varies according to the amount of light passing through the glass. To ensure that temperature was in no way affecting the experiments, one of the bars was placed in a trough of water so that there was about an inch of water for the light to pass through, but the results were the same; and when a strong light from the ignition of a narrow band of magnesium was held about nine inches above the water, the resistance immediately fell more than two-thirds, returning to its normal condition immediately the light was extinguished."

These observations excited widespread interest and elicited some correspondence, which will be found in the volume of Nature for the year 1873 .

Later in the same year, Sale presented before the Royal 
Society the results of his researches, confirming the observations of Smith, and showing in addition that the part of the spectrum most active on selenium is just outside the red rays, at a place nearly coincident with the locus of the maximum of the heat rays. He showed further that the effect of light, on exposure, is instantaneous, but that on cutting off the light, the return to the normal resistance is not so rapid.

In 1874 Lord Rosse announced some experiments which he had made for the purpose of establishing that it was light and not heat which was the cause of the change. He compared the action of the selenium cell with that of a thermopile under similar conditions, and found no accordance between them at all. The non-luminous radiation from hot bodies had no action upon the cell, whereas the effect of candle light was not very materially diminished when allowed to pass throngh a plate of glass or a solution of alum.

Further confirmation of these results was supplied in 1875 by Siemens, who adds some very interesting information regarding the preparation of the cells. He found that no satisfactory results were to be obtained from material which had been transformed into the metallic modification by heating to $100^{\circ}$ or ${ }^{1} 50^{\circ}$, but that by long heating to $2: 10^{\circ}$ or even by cooling melted selenium down to $210^{\circ}$ and maintaining it at that temperature for some time, "another modification" as Siemens says, is obtained, and this shows a higher degree of conductivity as well as a normal behavior toward changes of temperature, the resistance rising as the temperature is raised. The action of light upon such material is also very much more marked, and entirely constant, the earlier cells having given variable results. Two flat spirals of platinum wire about I mm apart, between mica plates, formed the cell, and a layer of selenium was fused over the spirals so as to fill the interspaces. This formed a very sensitive instrument, and Siemens found that heat causes a diminution of conductivity, whereas direct sunlight increased it more than ten-fold, the increase being nearly proportional to the square root of the intensity of the light. In the same year appeared a paper by 
Adams, bringing further confirmation of the statement that the light rays alone are active. He found that a marked effect was produced by the light of the moon, and that of the various parts of the spectrum the greenish-yellow rays were the most powerful.

Practical application of these new properties of selenium was now made in the construction of instruments for the measurement of light intensities, etc. Thus in the year 1875 Siemens described his "Electrical Photometer", Bell his "Photophone" in I880, Bidwell his "Telephotograph" in I 88r, and so on. Since the construction of these instruments had added nothing to the theory of the matter in hand, a mere mention of them will suffice:

The year 1876 is rich in memoirs. Draper and Moss undertook to determine what they call the "precise molecular state" of light-sensitive selenium; but though they describe several forms of metallic selenium, which show varying behavior toward the electric current, nothing is said of the methods of their preparation.

Later, Moss made a study of the action of mercury vapor on rods of vitreous selenium and found that when these are allowed to stand over mercury, they acquire a film of high conductivity, no doubt selenide of mercury. The same result is obtained by dipping them into mercury. Rods of the metallic modification also show increased conductivity under like circumstances. Adams, in the same year, showed that the change in resistance of selenium under light stimulus is proportional to the square root of the illuminating power. Experiments with tellurium cells indicated a distinct though very slight influence of light upon their conductivity. Adams and Day then showed that there is a change of resistance when the direction of the current passing through a selenium cell is reversed. Their method of preparation of the cell was to fuse platinum wires against the ends of a rod of vitreous selenium and then place this in a bath of hot sand for some time. They showed, moreover, that, on the whole, there is a general diminution of resistance in the selenium as the battery power is increased. 
Their results indicate that the conductivity of selenium cells is electrolytic. After passing the current for some time through the selenium, and then disengaging the electrodes from the battery and connecting them with the galvanometer, a current, sometimes of considerable intensity, was set up in the opposite direction, thus showing a polarization effect. Light has an action upon this polarization current; indeed they found that light is capable of setting up a current in such an arrangement even where no current has previously passed. The sensitiveness is different in different parts of the same piece of selenium, but in general the current is set up from the less towards the more illuminated regions. It is produced instantaneously and falls at once to zero when the light is shut off. When the light fell upon a junction, the current passed from the selenium to the platinum, through the junction.

A most important contribution to a knowledge of the subject was supplied in this year by Siemens. He endeavored, in the first place, to find other substances showing a behavior to light similar to that which is manifested by selenium, but in vain. Even in the case of tellurium, to which Adams had attributed this property, Siemens could find no distinct action which could not be explained as a heat effect.

In order to repeat the observation of Hittorf under better conditions, he prepared a cell with vitreous selenium and carbon electrodes. This was connected to a single Daniell cell and plunged into a bath of paraffin maintained at $280^{\circ}$. A thermometer standing in the centre of the cell showed the change in temperature in the mass of the selenium, and any differences in its conductivity were read off upon a galvanometer. The results are shown in the accompanying diagram (Fig. 4).

The curve $A$ represents the temperature of the selenium, the curve $B$ the conductivity, and $C$ represents a normal change of temperature for the conditions of the experiment. Time is plotted on the horizontal axis and the values upon the vertical axis indicate temperatures for the $\mathrm{A}$ and $\mathrm{C}$ curves, and conductivities for the $\mathrm{B}$ curve. 
Considering first, the $\mathrm{A}$ and $\mathrm{C}$ curves, we find that at about $100^{\circ}$ where the transformation into the metallic form would naturally begin, there is an abnormal rise in temperature. This is due to the heat of transformation. On the other hand, when we come to about $220^{\circ}$ there is a retardation because we have arrived at the melting-point; after complete fusion, the two curves run together again. Consider now the A and B curves. Siemens records that at $80^{\circ}$ there was still complete non-conduction; when the thermometer had reached $I 62^{\circ}$ the deflection of the galvanometer had risen to 870 scale divisions; plainly by

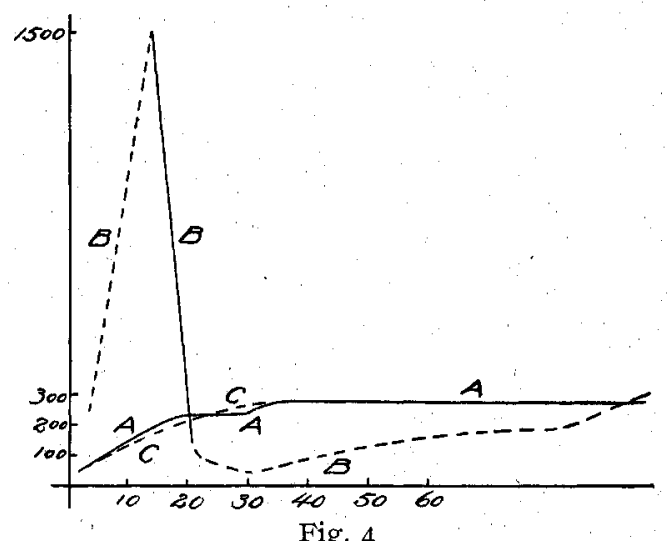

this time a good deal of the material had gone over into the metallic (conducting) state. At $200^{\circ}$ the deflection was $5^{22}$, but when the thermometer registered $215^{\circ}$ it had fallen to $I 20$ scale divisions. The thermometer, being in the middle of the mass, shows a certain lag, so that this reading of $215^{\circ}$ doubtless corresponds to a higher temperature throughout the mass, and the fall of conductivity is due to the fact that a good deal of the selenium had already passed into a state of fusion. At about the time that complete fusion is reached, the conductivity shows a minimum, and after that, with constant temperature, it rises gradually to the end of the experiment, the temperature of the selenium remaining at about $250^{\circ}$ to the last. The conclusion drawn from these observations by Siemens, that metallic sele- 
nium shows increasing conductivity with rising temperature, rests on insufficient ground, because the entire period between the beginning of the experiment and the moment when the melting-point was reached was less than twenty minutes, and five minutes of this time were occupied in raising the temperature to $100^{\circ}$. During the remaining period, there was probably a continuous change going on from the vitreous to the metallic modification, which would, of itself, bring about an increase of conductivity until the change in this direction, in the cooler parts of the cell, was balanced by a change in the opposite direction, due to fusion, in the hotter parts.

Later experiments, however, showed that the conductivity of gray selenium does increase with rising temperature.

The gradual rise in the $\mathrm{B}$ curve is difficult to explain except on the ground of chemical action. Shelford Bidwell has shown, in a paper published somewhat later, that the peculiar behavior of selenium cells may be due to the formation of selenides. Such a reaction might easily go on in this case with the metallic impurities contained in the carbon electrodes; but of that more will be said later.

In another experiment, where the direct heat of a flame was used, Siemens found that the conductivity increased up to $35^{\circ}$, where rapid vaporization of the selenium set in.

The remark of Siemens that in the case of both solid and liquid selenium the conductivity decreases with continued heating, stands in unexplained contradiction with the results of the above experiment.

If the current be passed for some time, Siemens finds a diminution of conductivity as if polarization had set in, opposing itself to the passage of the current.

Experiments made with metallic selenium prepared by heating the vitreous form to $5^{\circ}$ show that the conductivity does slowly fall when the temperature is kept constant, and also that a higher result is always obtained at a given point of temperature by cooling down to it, than by heating up to it.

Siemens passed next to the use of other electrodes, namely 
those of platinum and iron, having, as he says, satisfied himself that solid selenium did not attack these metals. Yet it will be seen that in all the preparations he used, it was not solid selenium alone which came into contact with the metals, but liquid selenium as well, and at high temperatures. The electrodes in these experiments were either in the form of spirals, or lattice work, so as to expose a maximum surface of contact with the selenium while permitting of full illumination. On the effect of changing temperatures, the following experiment is worth transcribing:

Two cells, numbered 33 and 36 , were placed in a paraffin bath, whose temperature was then rapidly raised to $200^{\circ}$. Both cells began to conduct at about $100^{\circ}$ and reached a maximum at $200^{\circ}$. Cell No. 33 had then a conductivity of 2720 , No. $3^{6}$ of $2 \mathrm{I} 2 \mathrm{O}$, in arbitrary units. The temperature was maintained for four hours.

The change with the time is shown in the table:

\begin{tabular}{c|c|c}
\hline & \multicolumn{2}{|c}{ Cond. } \\
\hline Time elapsed & No. 33 & No. 36 \\
\hline I hr & & 940 \\
$2 \mathrm{hr}$ & 1240 & 820 \\
$4 \mathrm{hr}$ & 1090 & 800 \\
\hline
\end{tabular}

No. $3^{6}$ was then rapidly cooled, and No. 33 , being slowly cooled, gave the following readings:

\begin{tabular}{c|c}
\hline Temp. & Cond. \\
\hline $180^{\circ}$ & 1020 \\
150 & 2460 \\
130 & 5730 \\
120 & 8320 \\
100 & 17020 \\
80 & 21280
\end{tabular}

after which it diminished. On the following day it showed, 
at ordinary temperatures, a conductivity of 6190. Meanwhile No. 36 when suddenly cooled to room temperature, had been found to have a conductivity of I6450; after half an hour, of I 4330 ; and on the following day 7710 .

Thus these cells show a decreasing conductivity, when maintained at $200^{\circ}$, but when cooled down, whether slowly or rapidly, the conductivity rises rapidly. This is in direct opposition to the results obtained with metallic selenium prepared in the ordinary way. The difference in preparation is that the "ordinary" form is made by heating vitreous selenium to $150^{\circ}$, whereas this form is produced when the same material is heated to $200^{\circ}$. But it must be noticed that the experiments on the other form were made with quite a different kind of cell, provided with carbon poles. The cell in these later experiments, by exposing so large a surface to the selenium, increases very much the possibility of a marked influence dne to the formation of selenide at the surfaces of contact.

Bellati and Lussana ${ }^{2}$ have measured the conductivities of metallic selenides and they find that, in general, these compounds show increasing resistance with rising temperature; i. e., they conduct like metals. Furthermore, they find, in the case of copper and silver selenides, curious breaks in the curves at higher temperatures. It seems, therefore, not at all improbable that the change in selenium cells by long heating at $200^{\circ}$, which causes them to conduct metallically, may be explained by the formation of selenides.

Siemens finds that a cell which is only heated for a short time to $200^{\circ}$ does not behave differently from one containing the ordinary metallic modification. In order to give to the cells the property of metallic conduction, it is necessary that the selenium should be first in the vitreous state, and that this should then be heated directly to $200^{\circ}$. If it has first been heated for some time at $100^{\circ}$ and the temperature subsequently raised to $200^{\circ}$, the effect is either not produced at all, or to a far less degree. Nor does selenium which has been melted and cooled

${ }^{1}$ Att. Inst. Veneto (6) 6, I89 (I887), or Ostwald's Lehrbuch, II, 2, 422. 
to $210^{\circ}$ and then maintained at that temperature, display any abnormal behavior. It conducts like ordinary crystalline selenium.

Now vitreous selenium when heated to $200^{\circ}$ is quite soft, and would be much more likely to attack metallic surfaces than the crystalline form, so that it is natural to suppose that in so far as the formation of selenide may be responsible for the behavior of these cells, the method of heating adopted by Siemens would be most:likely to produce the effect desired. By heating at $100^{\circ}$ the mass would be almost entirely transformed at a temperature where it would be much less likely to act on the metals, and we would not expect to find any very marked reaction on heating this then to $200^{\circ}$.

But the second observation of Siemens recorded above, regarding the failure to prepare cells by cooling down' fused selenium to $210^{\circ}$ is, as he himself points out, in contradiction with his earlier experiments in the same direction, and it is certainly not plain why this method of preparation should not bring about as good results as the other.

From the remaining experiments reported in this paper, the following conclusions are drawn: The observation of Adams that the conductivity of selenium cells increases for higher electromotive forces, is confirmed for such cells as have been prepared by heating vitreous selenium at once to $200^{\circ}$, but not for those where the transformation has been effected at lower temperatures. The effect of a continued passage of a current through a cell is the same as if a heating were thereby produced, i. e. for one kind of cell it causes a tise, for the other a fall in conductivity. The change is shown not to be due to temperature. Reversing the current brings about such various phenomena that no general statement can be made about them. In some cells there is no effect at all; in others, evidence of a polarization current.

With the cells prepared at $200^{\circ}$, if the heating at that temperature has been sufficiently long continued, so that the conductivity has attained a constant value, then when the tempera- 
ture is lowered the conductivity shows an immediate rise. If the heating was less protracted the conductivity falls at first with falling temperature, reaches a minimum, and then rises again. The position of this minimum on the scale of temperature is dependent upon the length of the previous heating.

"Selenium shows an extraordinary behavior on change of temperature. It assumes a new conductivity value at once when the temperature is altered, and this change for rising temperature is in the direction of higher conductivity, if the selenium is of the first form (ordinary metallic), lower conductivity if it is of the second (prepared at $200^{\circ}$ ). But the new value does not remain constant. For the second form, it falls after every change of temperature, no matter whether this change be up or down, and approaches a limiting value, slowly at first, then more rapidly. The farther below the turning point (minimum, see above) the new temperature lies, the greater is the conductivity which is at first manifested, but the more rapid also is its diminution. If the selenium has been maintained for some time at a lower temperature so that its conductivity has fallen to a minimum, the peculiar phenomenon may be observed with the second form, that a rise of temperature brings with it at first an increase of conductivity. This is followed by a fall, and the end value is of course less than that for the lower temperature."

Cooling to $-15^{\circ}$ destroys the peculiar properties of the second form and converts it apparently into ordinary metallic selenium.

Siemens noted the influence of the size of the surface of the electrodes on the behavior of the cell, and also the importance of uniform contact between the selenium and the metal.

In explanation of the extraordinary behavior of the element, he assumes that a third form is produced by continued heating at $200^{\circ}$, that this form is only stable at that temperature, and is at lower temperatures prevented from complete decomposition by being dissolved in, or combined with, ordinary metallic selenium. This view offers an explanation of the turning point, beyond which the character of the conduction changes from 
metallic to electrolytic, and also of the fact that the cells show such a remarkable lack of uniformity of behavior with changes of temperature.

That this assumption of a second form of metallic selenium has met with no support in my own experiments, has been shown above. Whether it will be possible to clear up all of Siemens' results by a further study of the infuence of selenides upon the conductivity of selenium cells, must remain for the present an open question. Meanwhile, it is to be remembered that many of the irregularities which he noted may have had their seat in changing and irregular contact between selenium and metal; the cells were prepared with vitreous selenium, and when this goes over to the metallic form, there is, as we know, a very considerable diminution in its volume; this would tend to cause rupture at any surface of contact as well as to introduce air cavities everywhere through the material.

Lenher and Morgan, ${ }^{5}$ in their experiments on the conductivity of tellurium, found that alterations in the contact between the material and the electrode used, caused the widest variations in their results. Indeed the best values they could get are very far from uniform.

In the year I 877 , there appeared a second paper by Siemens, devoted to a more detailed consideration of the action of light. He finds the greatest activity in the red region of the spectrum; concludes that there are too many disturbing influences in the measurements to make it possible to find any fixed relationship between the light intensity and the resulting change of conductivity; and, finally, presents some detailed experiments on the effect of continued illumination upon the cells.

At the same time, Forssmann announced the results of some extended experiments upon the action of light of different colors. His first results go to show a maximum effect in the red and yellow, a minimum in the green; but he found indications later on, that even invisible rays may produce an effect. For instance, lamp-light which had passed through a

' Jour. Am. Chem. Soc. 22, 28 (1900). 
solution of chromic chloride had a larger effect than the direct light itself, although the color of the chromic chloride was so intense that it was opaque to the eye even in direct sunlight. Other salt solutions were studied as well, but no general conclusions could be drawn from the results.

In the following year ( 1878 ), Sabine published a paper on "some electrical experiments with crystallized selenium" in which he brings out very clearly the enormous importance of the junctions in the behavior of selenium cells. "A large portion of the observed resistance of a so-called selenium resistance may, and frequently does reside in the junctions and not in the selenium." The same is shown to apply also to the alterations brought about by inversion of the current. Light and heat appear from his experiments to act in the same way upon the conductivity of selenium surfaces; and, finally, the alterations brought about by these means, are shown to be probably in the nature of an actual change in resistance, rather than, as some investigators have supposed, an electromotive force set up in the selenium in the same direction as the battery current.

Alexander Graham Bell, in I88o, presented an account of his practical applications of the selenium cell in the construction of the photophone. He found that "brass, although chemically acted upon by the selenium, forms an excellent and convenient material. Indeed, we are inclined to believe that the chemical action between the brass and the selenium has contributed to the low resistance of our cells by forming an intimate bond of union between the selenium and the brass." There is but little of theoretical interest in the paper, except that Bell finds the long heating and slow cooling formerly recommended in the preparation of selenium cells, to be unnecessary; this is probably because selenium acts more rapidly upon brass than upon platinum.

Obach (I880) found that phosphorescent light caused a change in the conductivity of selenium. The phosphorescent material used was of unknown composition, but being a commercial article was probably one of the alkaline earth sulphide 
preparations. Its action was relatively slight, yet distinct. Strangely enough, it was entirely cut off by the interposition of red or yellow glass; while blue glass transmitted six-sevenths of the original effect.

There is through these years a large amount of literature on the applications of selenium cells, scattered through such journals as Nature, the Journal of the Society of Telegraph Engineers, etc. I have been at no special pains to collect references to such letters and short communications except in the cases where some fact of theoretical importance has been brought out. The best general account of this side of the subject will be found in Bell's paper cited above.

Kalischer's article in I88I under the title of "photophone without battery," describes his attempts to produce a photophone in which the current was supplied by the electromotive force of the selenium preparation itself under illumination.

Moser ( $188 \mathrm{r}$ ) records some very interesting observations on the nature of the contact between selenium and metals : "On a copper plate I melted amorphous selenium and put on it a second metal plate of zinc or copper. Then I heated gradually so that the selenium became crystalline; and I then annealed it. Whilst the annorphous selenium adheres very well to the metal plates, these cells proved very brittle when the selenium was crystalline. The selenium always split off from the copper plate. ... Every lamina which split off was on the upper side light gray, and on the lower side blue black, not brilliant, but dull. In the same way, the copper plate had now a similar dtill bltteblack covering. This blue-black body is cuprous selenide. ... This experiment shows that between the copper and the selenium, or rather the cuprous selenide, there is only a slight and imperfect contact."

The view advanced by Moser that "selenium is heated by light" and that the changes in its conductivity are produced through the expansion of the mass of selenium and consequent tightening of the contacts was disproved by Shelford Bidwell in $\mathbf{1} 883$. We have seen too that experiments made some 
years previous had shown that the peculiar action of selenium cells could not be explained as a heating effect.

Fritts, in I 883 , described the preparation of selenium cells of hitherto unattained sensitiveness and of very low resistance. One of them showed fifteen times as high a resistance in the dark as it had in ordinary diffused daylight of the room. $\mathrm{He}$ finds that the best metals to use are "brass, zinc, or iron or copper thinly coated with tin". (Apparently only the copper was tin-plated.) The properties of these cells are in other respects also, quite unusual. It is found, for example, that the kind of battery has a great deal to do with the result; thus some cells which were light sensitive when operated with a Leclanché battery gave no results at all with a bichromate battery. The effect of rapidly alternating currents was in some cases to reduce the resistance of a cell from many thousands of ohms to almost nothing; in other cases to raise it from next to nothing up among the thousands. These extremely variable results are left quite without explanation.

Fritts describes, in the latter part of his paper, the preparation of a new modification of selenium. The method of preparation is only imperfectly indicated, but seems to be by prolonged heating of selenium on a brass plate (to what temperature?) and then gradually cooling, under pressure. "The plates so made have portions which are transparent, situated apparently where the temperature was highest. The remaining portions of the plates are black and red, interspersed with gray. Thus upon one plate may be seen selenium in four different states or colors. ... A small portion of the transparent selenium having, perhaps, one-half square inch of surface, had a resistance of only three ohms. It was found to be affected by light very little, if at all."

This transparent film which he considers as a new modification of the element, was perhaps in reality a film of fused selenide; or, it may have been a thin film of vitreous selenium, which is almost colorless in very thin layers. In the latter case we must assume an experimental error in the measurement of its resistance. 
Selenide of zinc is described as a reddish-yellow substance. It is possible that this may have been the transparent material observed by Fritts.

In I884, Bidwell, in a short article on the resistance of sulphur and selenium cells, showed that sulphur also gives lightsensitive cells when it contains sulphide of silver, and that selenium which has never come into contact with a metal possesses a resistance enormously higher than the ordinary material in the selenium cell. In a longer article, in I885, the same author puts forward the hypothesis that the peculiarities of the selenium cell are really due to the presence of selenides. If this is the case, then the conduction may very well be electrolytic and would lead to the deposition of free selenium at one electrode and of the metal at the other. A change of this kind in the nature of the contacts might easily give all the remarkable irregularities in the behavior of selenium cells which have been recorded as the results of (I) a steady passage of the current, and (2) a reversal of its direction.

Kalischer (1887) studied the conditions under which the selenium cell becomes, as that author says, photoelectromotive. The cells have the ordinary form, but are constructed of two different metals, the selenium forming a connection between them. Copper and zinc were found to be a very efficient pair. They have, as a rule, a comparatively high resistance. "Besides the copper-zinc combination, I have used also copper-brass, zinc-brass, and copper-platinum. In all of these, the direction of the current which is called forth by light, is the same as in the ordinary galvanic elements. Thus, for instance, from zinc through the selenium to the copper." Nevertheless the same results may be obtained, using only one metal for the electrodes, though the current is less marked in this case. With lapse of time, the cells lose their power, and this loss is coupled with a decrease in resistance.

It is in this direction that most of the more recent work on selenium cells has been done. Thus v. Uljanin (I 888) and Righi ( 1888 ) have both made important contributions to our knowledge of the electromotive force of selenium in the light. 
Righi (1889) finds further that a selenium cell constructed with electrodes of different metals, shows an electromotive force even in the dark.

Hesehus (1884), in a purely theoretical paper, discusses the different explanations which have been suggested for the abnormal conductivity of selenium, and favors the assumption of two metallic forms of the element - Siemens' idea.

Bidwell in $189 \mathrm{I}$ carries on the argument in favor of the theory that the behavior of selenium cells is due to selenides. He shows that the "annealing" of the cell which has almost always been regarded as absolutely necessary to the production of good light-sensitive cells, would in reality lead to the formation of a film of selenide at the junction. The deterioration of the cells with age, he attributes to the gradual thickening of the layers of selenide at the expense of the free, badly-conducting selenium, and thus the resistance of the cells slowly falls. "At length the layers of selenide become so thick that the coatings upon the two wires actually meet and touch each other. Thereupon the cell is short-circuited; its resistance no longer depends upon the selenium, but upon the metallic selenide, which is a good conductor."

The deposition of free selenium upon the electrode in the form of a covering of red tufts was shown experimentally. This material is amorphous selenium which, as we know, is a good insulator; hence the alterations in conductivity produced by continued use of the cell may well be large.

Since the appearance of this paper of Bidwell's no great addition has been made to the knowledge of the subject. Siemens, in his important paper, advanced the theory of a second form of metallic selenium, produced at $200^{\circ}$. That is the only good explanation, other than Bidwell's, which has been offered. Now we have seen in the other sections of this paper that it has been quite impossible to get any direct evidence of the formation of a new modification of seleninm at higher temperatures. Furthermore, even granting its existence, there are still very many of the recorded observations which cannot be explained satis- 
factorily on that ground. The hypothesis of Bidwell gives much more hope of an ultimate clearing up of all the known facts. We have seen that selenides are undoubtedly produced when selenium is heated in contact with metals; that those metals copper and brass - which are the most efficient in yielding sensitive cells, are among the ones most readily attacked. Hence the presence of selenides is certain. Bidwell has shown that there is a deposition of amorphous selenium at the anode, which would hardly be the case if the conduction were not really electrolytic. This deposition may well be the catise of the extraordinary differences observed on the reversal of the current, etc. Selenides are known to be good conductors ; unfortunately the action of light upon them has not been studied; but the fact that sulphur which contains silver sulphide displays the lightsensitiveness of a selenium cell supplies an argument by analogy, of considerable force.

Furthermore, Bidwell found that a silver leaf placed upon glass and painted over with a solution of sulphur in carbon disulphide, if only partly shaded from the light, became, after fifteen minutes, dark brown in the illuminated part, while remaining whitish yellow where shaded. It may be mentioned here that Schuller ( $188_{3}$ ) found that when selenium is distilled there is a residue left containing copper and lead; this indicates that the commercial material is probably always more or less contaminated with metals.

It has recently been announced (I 900 ) by Perreau that the resistance of selenium cells is reduced by X-rays, in the same way as by light.

So much of the time spent in the study of selenium cells has been devoted to the devising of instruments which have in the end proved inefficient that, in spite of the large literature of the subject, very few really scientific observations are on record. By beginining now with a methodical study of the behavior of selenides, and of selenium and selenide mixtures of known composition, there is every hope that a conclusion might be reached which would set the whole matter on a firm basis and supply 
moreover an interesting chapter on the action of light on chemical compounds.

\section{I0. Coefficient of expansion}

Fizeau (I869) gives the value for the linear coefficient of expansion for vitreous selenium as 0.0000368 . It is to be inferred that the experiment covered a range of temperature from $10^{\circ}$ to $80^{\circ}$, and the value given above represents a mean result for $40^{\circ}-50^{\circ}$.

Spring (I88I) made a determination of the cubical expansion of selenium in the crystalline (metallic) form; the results are given below; the first series refers to the powdered crystals; for the second, these were subjected to a pressure of 6000 atmospheres, to get rid of air cavities. $s$ is the specific gravity, $\beta$ the mean coefficient of expansion from $0^{\circ}$ to $t^{\circ}$.

\begin{tabular}{|c|c|c|c|c|c|c|c|}
\hline & $t$ & $0^{\circ}$ & $20^{\circ}$ & $40^{\circ}$ & $60^{\circ}$ & $80^{\circ}$ & $100^{\circ}$ \\
\hline I & $\begin{array}{l}s \\
\beta .10^{7}\end{array}$ & $4.73^{12}$ & $\begin{array}{c}4.7176 \\
1478\end{array}$ & $\begin{array}{c}4.7010 \\
1635\end{array}$ & $\begin{array}{c}4.6826 \\
I 743\end{array}$ & $\begin{array}{c}4.6623 \\
1857\end{array}$ & $\begin{array}{c}4.6396 \\
1981\end{array}$ \\
\hline II & $\begin{array}{l}s \\
\beta .10^{7}\end{array}$ & 4.7994 & $\begin{array}{c}4.7869 \\
\text { I } 307\end{array}$ & $\begin{array}{c}4.7699 \\
1539\end{array}$ & $\begin{array}{c}4.7526 \\
1644\end{array}$ & $\begin{array}{c}4.735 \mathrm{I} \\
1803\end{array}$ & $\begin{array}{c}4.7 \text { I } 67 \\
\text { I } 75 \text { I }\end{array}$ \\
\hline
\end{tabular}

It will be noticed that the specific gravity in each of these cases is somewhat less than the value to which the best of the other determinations have led. Spring's method was that of the weight thermometer filled with water; hence it would not be surprising if the material contained noticeable air cavities; this would explain the higher results for the uncompressed selenium.

\section{GENERAL PROPERTIES OF THE ELEMENT}

\section{Atomic weight}

The first determinations are those of Berzelius (I8I8), and his results have only been confirmed by the latest and most accurate experiments. He found that I gram of selenium gave, when treated with chlorine, 2.79 grams of $\mathrm{SeCl}_{4}$. This gives the atomic weight as $79.2(\mathrm{Cl}=35.45)$. As a control experiment the chloride was transformed into the acid $\mathrm{H}_{2} \mathrm{SeO}$, and the hydrochloric acid thus liberated determined by silver nitrate. The 
chloride obtained from one gram selenium yielded, in this way, 7.2285 grams silver chloride, from which we calculate the value $79.35^{\circ}$

Berzelius did not, as Ostwald ${ }^{x}$ states, lay the greater emphasis on the first value; on the contrary, he gives as the most probable result, the mean of the two, but he does state that of two such double determinations which he made he considers the first as the better, because it was made with the larger quantity of material. By another method he found that r.888 grams of silver selenide, $\mathrm{Ag}_{2} \mathrm{Se}$, yielded r.844 grams of silver chloride, from which the atomic weight is found to be $77.98(\mathrm{Ag}=107.9)$.

The analysis of barium selenate quoted by Ostwald was not made as a determination of atomic weight. The same remark applies to the work of Mitscherlich and Nitzsch who made an analysis of selenic acid.

The next atomic weight determination is therefore that of Sacc ( 1847 ); in this case also several analyses of salts were made, which were recognized by that author as being unsuitable for atomic weight determinations. The methods upon which he laid stress were:

(I) The reduction of selenium dioxide by ammonium bisulphite and hydrochloric acid. This method yielded the results $78.3-78.2-79(\mathrm{O}=\mathrm{I} 6)$, and

(2) The reduction of barium selenite by the same reagents, and weighing the mixture of barium sulphate and selenium which is precipitated. This is a less accurate method, and gave, as the mean of three determinations, about 78.6 .

Erdmann and Marchand (1849) analysed mercuric selenide and found that it contains $71.726-7 \mathrm{r} .73 \mathrm{I}-7 \mathrm{r} .74 \mathrm{I}$ percent of mercury. These values give as the atomic weight $78.96,78.96$ 78.93.

Dumas (1859) made a series of determinations in which he converted known weights of selenium into the chloride $\mathrm{SeCl}_{4}$. His results vary from 79.2 to 79.66 and give as a mean value 79.46. As pointed out by Meyer and Seubert, Dumas has re-

I Lehrbuch, I, ro6. 
corded in his article, in every case, the increase of weight as if it were the total final weight - i. e., what he calls the weight of chloride is really the weight of the absorbed chlorine.

Petterson and Ekman (1876) used two different methods:

(I) By weighing the silver obtained from silver selenite by heating, they obtained seven values varying between 78.90 and 79.18, and giving in the mean 79.01 .

(2) By reducing weighed quantities of selenions acid by means of sulphur dioxide and determining the weight of the selenium precipitated, they found in five results a variation from 79.06 to $79.10 ;$ in the mean 79.08 .

They consider the second method the more trustworthy and give the value 79.08 as representing most nearly the true atomic weight.

Finally, Lenher (1898) made a very careful study of the problem by the following methods:

(I) Silver selenite was converted into silver chloride; in this way, eleven results were obtained varying from 79.263 to $79 \cdot 326$.

(2) The silver chloride so obtained was then reduced in the case of eight of these, and gave values between 79.277 and 79.369 .

(3) A weighed quantity of the bromide $\left(\mathrm{NH}_{4}\right)_{2} \mathrm{SeBr}_{6}$ was reduced by hydroxylamine and the resultant selenium weighed. Eight determinations gave values between 79.226 and 79.367 . Lenher's mean values are:

From silver chloride 79.329 (eleven results)

From metallic silver 79.329 (eight results)

From bromide 79.285 (eight results)

The general mean is therefore $79.3 \mathrm{I}$.

The values given in the most recent standard tables of atomic weights are as follows:

German Chemical Society, Ber. 3I, 276I (1898) 


\section{Boiling-point}

Carnelley and Williams (I879) found a value lying between $676^{\circ}$ and $683^{\circ}$. Their method of determining the temperatures was by using substances of high melting-point previously determined, and exposing them to the vapor of the boiling liquid.

Troost (I 882) found the boiling-point to be at about $665^{\circ}$ under a pressure of $760 \mathrm{~mm}$. The temperature was measured with a form of air thermometer.

\section{Vapor-density}

Sainte-Claire Deville and Troost (I863), in their researches on vapor-density at high temperatures, determined that of selenium at $1420^{\circ}$ and found it to be 5.68 , corresponding to a molecular weight of 164.0 . The values for the molecular weight at lower temperatures are:

\begin{tabular}{cc}
\hline \\
At $1040^{\circ}$ \\
At $860^{\circ}$ & Mol wt \\
222
\end{tabular}

\section{Spectrum}

In 1863 Werther published a note on the similarity between the spectra of selenium and lead. Ditte (I87I) made a comparative study of the spectra of sulphur, selenium, and tellurium. He found well marked yellowish-green lines in the selenium spectrum toward the $\mathrm{E}$ line, and also two brilliant blue bands near to and to the left of the $G$ line.

The work of Salet as well as that of Plïcker and Hittorf is summarized in the report of a special committee of the British Association for the Advancement of Science (I884). The tables there given are too long to be quoted here.

\section{Absorption spectrum}

Gernez (1872) records that the vapor of selenium absorbs the rays of the spectrum up to about the $\mathrm{C}$ line; but at higher temperatures there is extinction in the blue and violet. 


\section{Capillarity constant}

Quincke (r868) determined the capillarity constant of selenium by the method of drops, and found

$$
a=7.180 \mathrm{mg} \text { for } 2 r=\mathrm{Imm} \text {. }
$$

\section{CONCLUSION}

In conclusion, I desire to express my sincerest thanks to Professor W. D. Bancroft, in whose laboratory this work was carried on; I am indebted to him not only for suggesting the subject of the investigation to me, but also for his continued interest and timely suggestions while it has been in progress.

Cornell University, May, rgoo. 